\title{
A comparative framework to support an ecosystem approach to fisheries in a global context
}

\author{
Emma M. Lockerbie $^{1,2}$ Lynne Shannon $^{1,2}$, Christopher P. Lynam $^{3}$, Marta Coll $^{4,5}$ and Astrid Jarre $^{2,6,7}$
}

\begin{abstract}
Although an ecosystem approach to fisheries has been recognized as a means of progressing toward sustainable fishing, successful implementation of this approach has been limited. However, one way in which progress has been made is through the use of suites of indicators. Decision tree frameworks can be used to incorporate trends in ecological, fishing, and environmental indicators into ecosystem assessments. A relatively generic decision tree framework has been developed and successfully applied to multiple ecosystems. This framework incorporates trends in indicators, as well as the impacts of fishing pressure and environmental variability on ecological indicators in order to assess the state of each ecosystem. The inclusion of ecosystem expert knowledge from the outset ensures trends are correctly interpreted and allows analyses to contribute to global comparisons in a robust and meaningful manner. Although ecological and environmental indicators are well developed, those addressing the human dimensions of marine ecosystems are less so. This framework holds the potential to incorporate such indicators in order to fully assess marine ecosystems in a comparative context. Such assessments could help ensure food security from marine resources into the future as well as ensuring the well-being of coastal communities. Here critical review of the potential value of this framework has been conducted, with its usefulness emphasized in the similarities it holds, and in the contribution it could make, to current global methods of ecosystem assessments.
\end{abstract}

Key Words: comparative assessment; decision support; decision trees; ecosystem approach to fisheries; indicators

\section{INTRODUCTION}

Fisheries are known to impact marine ecosystems in many ways, not only through the direct removal of target species, but also through habitat destruction, shifts in community structure, as well as population dynamics, and changes to ecosystem structure and functioning (Soma 2003, Pickitch et al. 2004, Rochet et al. 2005). Unsurprisingly, this has led to increasing concern over ecosystem degradation on a global scale in recent decades.

Globally, fisheries provide an important food resource and offer employment to millions. Since 1961 the annual global increase in fish consumption has been twice as high as population growth, with marine capture fisheries providing the bulk of the resources (FAO 2018). It is therefore imperative to manage marine fisheries in a way that ecosystem goods and services can be maximized, while still providing both social and economic benefits (FAO 2018). To achieve this, there has been a global move toward implementing an ecosystem approach to fisheries (EAF). As defined by the FAO (2003:6), "an EAF aims to balance diverse societal objectives, taking into account knowledge and uncertainties about abiotic and human components of ecosystems and their interactions and applying an integrated approach to fisheries within ecologically meaningful boundaries." Because fisheries are deeply imbedded within marine ecosystems it is crucial to consider the effects of drivers such as environmental change as well as economic and social needs, alongside the direct impacts of removing target species, in order to implement successful management strategies (Cury et al. 2005). However, despite widespread approval at the World Summit for Sustainable Development in Johannesburg in 2002 and formalization in 2003 (FAO 2003), there has been limited success in the practical application of an EAF. This is often due to the complexity of the ecosystems being considered, as well as resistance from various stakeholders, including fisheries managers. Yet even in the face of the obstacles encountered in recent decades, some substantial progress has been made toward successfully implementing an EAF.

Important progress has particularly been made in terms of the ecological dimension of an EAF, with countless studies assessing the impacts of fishing on the biological components of ecosystems. A key way in which this progress has been facilitated is through the use of suitable suites of ecosystem indicators, which allow the assessment of states and trends in marine ecosystems (e.g., Jennings et al. 2002, Shin et al. 2010, Anticamara et al. 2011, Shannon et al. 2014a, Coll et al. 2016). Such indicators reflect key ecosystem properties and can be both model- and survey-based. A wide range of indicators are being utilized in various aspects of fisheries management, with a noteworthy example being provided by the IndiSeas project. This project was established to investigate "EAF Indicators: a comparative approach across ecosystems" (Shin and Shannon 2010:686), and provides several examples of how indicators can be used to evaluate states and trends of multiple marine ecosystems (e.g., Shin and Shannon 2010, Shin et al. 2012, Coll et al. 2016). Currently, 27 ecosystems have been included in the IndiSeas project, allowing the relative state of each ecosystem to be assessed. Comparisons between multiple ecosystems can improve understanding of the structure and function of each system, making it easier to interpret change even in view of complexities such as the large size of the systems considered, their biophysical complexities, and nonlinear dynamics (Megrey et al. 2009). The evaluation of a range of

${ }^{1}$ Department of Biological Sciences, University of Cape Town, South Africa, ${ }^{2}$ Marine Research (Ma-Re) Institute, University of Cape Town, South Africa, ${ }^{3}$ Lowestoft Laboratory, Centre for Environment, Fisheries and Aquaculture Science, UK, ${ }^{4}$ Institute of Marine Science (ICM-CSIC), Barcelona, Spain, ${ }^{5}$ Ecopath International Initiative, Barcelona, Spain, ${ }^{6}$ Marine Ecology \& Fisheries Group, Department of Biological Sciences, University of Cape Town, South Africa, ${ }^{7}$ Centre for Statistics in Environment, Ecology and Conservation (SEEC), University of Cape Town, South Africa 
ecosystems, with contrasting exploitation levels and histories, as well as varying environmental conditions, can also help determine a range of indicator values against which relative states of ecosystems can be evaluated. A comparative approach will allow us to learn from ecosystems that are already degraded, in terms of what to avoid, how to potentially mitigate for detrimental ecosystem changes, and theoretically provide early warning signs of ecosystem degradation. Alongside this, there is also the potential to recognize and learn from ecosystems that appear to be improving under successful management of exploitation.

Recent studies of exploited marine ecosystems have highlighted the importance of detailed information about past and present exploitation strategies, mechanisms of productivity dynamics, and dominant ecological and environmental features in order to correctly interpret indicator trends (e.g., Shannon et al. 2014b, Heymans and Tomczak 2016, Fu et al. 2019a). In this regard, frameworks like IndiSeas rely on numerous multi-institutional collaborations, incorporating knowledge from ecosystem experts into assessments, ensuring that misinterpretation of indicator trends is avoided. Another example is the FAO, who have utilized expert knowledge to help validate individual country scores for the UN Code of Conduct for Responsible Fisheries (FAO 2002, Pitcher et al. 2006).

In many indicator studies, strong emphasis has been placed on the impacts of fishing because this is a pressure that can be managed and is typically, currently, the greatest pressure on fish communities. However, it has long been recognized that, in many systems, focusing solely on the impacts of fishing is not sufficient because indicators also respond to other pressures, such as those caused by environmental change (Walther et al. 2002, Large et al. 2013, Fu et al. 2015). Alongside this, the specificity in responses of indicators to fishing pressure and environmental variability varies between indicators and between ecosystems. Therefore suites of complementary indicators are employed, providing information on populations and communities within an ecosystem, as well as on pressures on these, to help disentangle observed changes caused by multiple stressors, and attribute changes in indicators to specific drivers (Shin et al. 2018).

Despite the clear value suites of indicators that include ecological, fishing, and environmental indicators, these suites do not adequately cover the human dimensions (Bundy et al. 2012) or those pertaining to governance, needed to successfully implement an EAF. It will therefore be necessary to develop and employ additional indicators capturing the human and governance dimensions in the future to fully determine and understand the changes transpiring in marine ecosystems. Such indicators will need to include social and economic indicators (Jepson and Colburn 2013), as well as indicators that assess the impacts of the new industries constantly entering the blue economy, such as renewable energy and mining for deep sea minerals (Pauli 2010). Although advancement has been made toward incorporating such indicators into the IndiSeas project (e.g., Bundy et al. 2017), the incorporation of the human dimensions into most indicator suites relevant to an EAF still requires substantial effort.

Because existing indicator suites encompass vast amounts of information about changes occurring at the ecosystem level, it is necessary to incorporate these indicators into a suitable framework that will allow this information to be synthesized in a transparent and repeatable way and presented in a form that could be of use to fisheries managers and stakeholders. Here we are referring to a framework that is analogous to a synthetic model that can be applied to each ecosystem. Using IndiSeas indicators, a framework has been developed that spans ecological, fishing, and environmental indicators and has been used to successfully assess state and trends in ecosystems of different types and from various regions (Lockerbie et al. 2016, Lockerbie et al. 2017a, $b$ ). This framework holds the potential to meaningfully contribute to the implementation of an EAF, providing information of changes occurring in individual ecosystems as well as the opportunity to implement a comparative assessment approach across multiple ecosystems. The framework has also been developed in such a way that additional suites of indicators, for example those assessing the human dimensions of the ecosystem, could be added in the future. Here we consider past and future evolution of the framework, its potential contribution to management approaches and the continued implementation of an EAF.

\section{METHODS}

Decision trees are a tool in multicriteria decision analysis and have been used to assess marine ecosystems in numerous studies (e.g., Mardle and Pascoe 1999, Soma 2003, Rochet et al. 2005, Jarre et al. 2008, Bundy et al. 2010, Bastardie et al. 2013). They allow the consolidation of multiple indicator trends to characterize an ecosystem state. The integration of several indicators can be particularly useful for assimilating different types of information and merging different objectives among stakeholders with varying interests. The aim of such frameworks is to provide "an effective means of communication between scientists and end users" (Starfield and Louw 1986:553).

Lockerbie et al. (2016, 2017a, b) developed a novel approach to applying a modified decision tree framework, assessing the state and trends in multiple marine ecosystems using indicators developed in the IndiSeas project (Table 1). These studies aimed to evaluate the practicality of applying a generic framework across ecosystems of varying type. The framework was intended to support the synthesis of ecological, fishing, and environmental indicator trends in a repeatable and transparent manner. A series of steps have been incorporated into the framework, assessing trends in all indicators and identifying the reasons behind observed trends, therefore providing a complete assessment of the state of the ecosystem (Fig. 1). Although other, similar, frameworks have been developed and applied to a variety of marine ecosystems (e.g. Bundy et al. 2010), this framework has several distinctive features (Table 2). First, a greater number of possible categories can be attributed to indicator trends. This allows a more nuanced understanding of observed trends, rather than categorizing trends as purely increasing, decreasing, or not changing. This process involved indicators being attributed a score, based on the significance and direction of detected trends, and allowed all indicator trends to be considered in the categorization of ecosystems.

Another key aspect of the framework discussed here is the possibility to divide data sets into distinct time periods. The division of data sets can be based either on shifts in environmental indicators or shifts in management (as will be seen in the North Sea case study summarized below). In the majority of previous 
Table 1. All IndiSeas derived indicators, including data sources, management objectives, and details of indicators (adapted from Coll et al. 2016). Daggers $\left(^{\dagger}\right)$ indicate those indicators that were combined into an indicator of "overall fishing pressure." Abundance and catch data provided by the Department of Agriculture, Forestry and Fisheries, South Africa and trophic level information determined from Fishbase (http://www.fishbase.org/search.php).

\begin{tabular}{|c|c|c|c|}
\hline Indicator & Data Source & Management Objective & Details \\
\hline Mean Fish Length & $\begin{array}{l}\text { Fisheries independent } \\
\text { surveys }\end{array}$ & Ecosystem functioning & $\begin{array}{l}\text { Allows tracking of the direct effects of fishing on a community (Shin } \\
\text { et al. 2005). Quantifies the relative abundance of large and small } \\
\text { individuals. }\end{array}$ \\
\hline Mean Lifespan & $\begin{array}{l}\text { Fisheries independent } \\
\text { surveys }\end{array}$ & $\begin{array}{l}\text { Maintaining ecosystem } \\
\text { stability and resistance to } \\
\text { perturbations }\end{array}$ & $\begin{array}{l}\text { Proxy for the mean turnover rate of species and communities. } \\
\text { Considered to be a measure of ecosystem stability and resistance to } \\
\text { perturbations. }\end{array}$ \\
\hline Survey Biomass & $\begin{array}{l}\text { Fisheries independent } \\
\text { surveys }\end{array}$ & Resource potential & $\begin{array}{l}\text { Represents biomass of all surveyed species. This is a complex indicator } \\
\text { because changes can result from changes in productivity/growth of } \\
\text { certain species as well as environmental changes (Bundy et al. 2010). }\end{array}$ \\
\hline Proportion of Predators & $\begin{array}{l}\text { Fisheries independent } \\
\text { surveys }\end{array}$ & $\begin{array}{l}\text { Conservation of } \\
\text { biodiversity }\end{array}$ & $\begin{array}{l}\text { Role of predators in ecosystem is essential because they act as } \\
\text { dampeners on the whole food web (Sala 2006). Depletion of predators } \\
\text { can lead to trophic cascades (Frank et al. 2006, Daskalov et al. 2007). }\end{array}$ \\
\hline $\begin{array}{l}\text { Trophic Level of Surveyed } \\
\text { Community }\end{array}$ & $\begin{array}{l}\text { Fisheries independent } \\
\text { surveys }\end{array}$ & Ecosystem functioning & $\begin{array}{l}\text { Provides the trophic position of organisms sampled in research } \\
\text { surveys (Rochet and Trenkel 2003). }\end{array}$ \\
\hline $\begin{array}{l}\text { Trophic Level of Modeled } \\
\text { Community }\end{array}$ & $\begin{array}{l}\text { Model data (excluding } \\
\text { zooplankton and } \\
\text { primary producers) }\end{array}$ & Ecosystem functioning & $\begin{array}{l}\text { Aims to cover the full community, not just those species sampled in } \\
\text { surveys. Calculated using Ecopath with Ecosim models (see Shannon } \\
\text { et al. 2009). }\end{array}$ \\
\hline Inverse Fishing Pressure $^{\dagger}$ & $\begin{array}{l}\text { Commercial landings } \\
\text { and fisheries- } \\
\text { independent surveys }\end{array}$ & $\begin{array}{l}\text { Maintaining ecosystem } \\
\text { stability and resistance to } \\
\text { perturbations }\end{array}$ & $\begin{array}{l}\text { Measure of resource potential because it reflects the part of the } \\
\text { community production dedicated to fishing, calculated as } 1 \text { / (landings/ } \\
\text { biomass). Inverted so that it would decrease under increased fishing } \\
\text { pressure to follow trends of other indicators. }\end{array}$ \\
\hline Landings ${ }^{\dagger}$ & Commercial landings & Resource potential & Provides knowledge of exploited marine species. \\
\hline Marine Trophic Index ${ }^{\dagger}$ & $\begin{array}{l}\text { Commercial landings } \\
\text { and estimates of trophic } \\
\text { level (empirical and } \\
\text { fishbase) }\end{array}$ & $\begin{array}{l}\text { Conservation of } \\
\text { biodiversity }\end{array}$ & $\begin{array}{l}\text { Measures the change in mean trophic level of fisheries landings. } \\
\text { Calculated from catch composition data collected by the FAO (FAO } \\
\text { 2004). This indicator is cut off at a trophic level of } 3.25 \text {. }\end{array}$ \\
\hline Trophic Level of Landings ${ }^{\dagger}$ & $\begin{array}{l}\text { Commercial landings } \\
\text { and estimates of trophic } \\
\text { level (empirical and } \\
\text { fishbase) }\end{array}$ & $\begin{array}{l}\text { Conservation of } \\
\text { biodiversity }\end{array}$ & $\begin{array}{l}\text { Measures the weighted mean trophic level of species exploited by the } \\
\text { fishery, representing the position level of the whole catch. }\end{array}$ \\
\hline $\begin{array}{l}\text { Intrinsic Vulnerability } \\
\text { Index (IVI) of landings }\end{array}$ & Commercial landings & Ecosystem functioning & $\begin{array}{l}\text { Based on life history and ecology characteristics (including maximum } \\
\text { length, age at first maturity, longevity, natural mortality, fecundity, } \\
\text { spatial behavior, and geographic range; for full details see Cheung et } \\
\text { al. 2007). Mean IVI is based on IVIs of all landed species, weighted by } \\
\text { contribution of each species to the landed catch. This indicator relates } \\
\text { only to the fish community. Note: data necessary to calculate this } \\
\text { indicator were only available for Period } 3 \text {. }\end{array}$ \\
\hline
\end{tabular}

studies data sets have been analyzed as a whole, with the goal of identifying trends across multiple decades. Although this method may give an indication of particularly strong trends occurring over time, there is also the possibility that certain trends may be masked. For example, many ecosystems have undergone significant regime shifts. If data sets are not separated and trends in indicators determined under each individual regime, it is possible no trends would be detected, when reality differing regimes often show opposing trends. Without the division of data sets in such cases, the results of the application decision trees would not accurately reflect changes happening within ecosystems.

Previous decision tree frameworks utilized as part of the IndiSeas project assessed only the impacts of fishing on marine ecosystems (e.g., Bundy et al. 2010). In the framework discussed here suites of ecosystem-specific environmental indicators are included, allowing the impacts of environmental drivers on marine systems to be included in the assessment process.
In line with other studies utilizing ecosystem indicators, this framework includes advice from local experts at every step. Ecosystem experts provide knowledge on potential biases in official data used to calculate indicator values. This ensures that the necessary adjustments to indicators in each ecosystem (as discussed below) are correct within the context of system dynamics. This also allows verification that the results of trend analyses have been correctly interpreted. The presence of expert knowledge from the outset also ensures that the applications of the framework are robust and meaningful within the context of global comparisons (Shin et al. 2012), which is particularly important for future applications of the framework.

Although possible redundancy of correlated indicators has been recognized in the IndiSeas project (see Coll et al. 2016), these redundancies had not been included in previous decision tree frameworks (e.g., Bundy et al. 2010). The addition of this step to the framework discussed here ensures that the results are not biased by complementary or redundant indicators. Possibly one of the most important features of the current framework, 
Fig. 1. The step-by-step process of applying the developed framework to a marine ecosystem. First, it must be determined whether the data series must be divided into distinct periods based on known shifts in drivers. Trends in ecological, fishing, and environmental indicators are then determined using linear regressions, and scores are attributed to indicators based on the direction and significance of observed trends. Fishing indicators are combined into one indicator of overall fishing pressure to simplify the decision tree framework. The impacts of fishing pressure and environmental variability are determined, and scores are adjusted to account for these impacts. A reduced weighting is applied to correlated indicators to account for potential redundancies. Then finally the ecosystem is attributed an "overall ecosystem score."

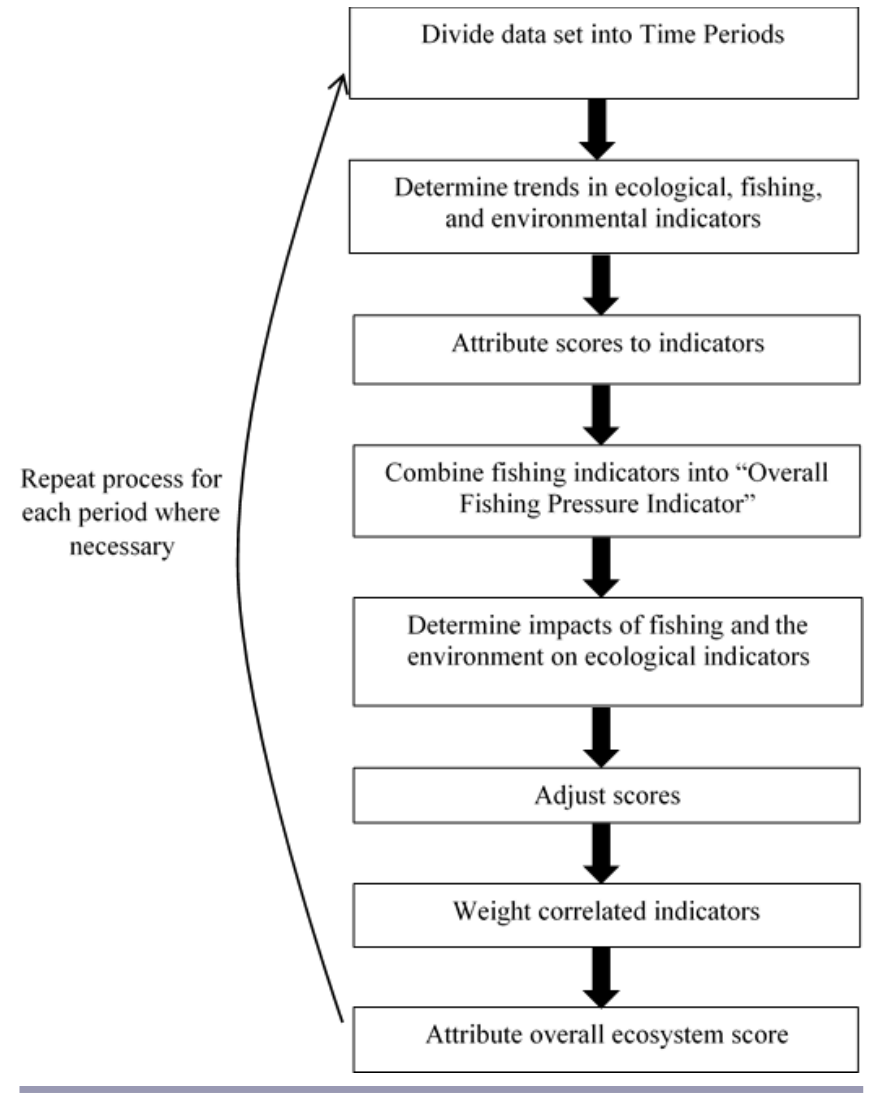

compared to those applied previously, is the fact that all indicator trends are considered before the ecosystem is classified. In previous decision tree frameworks utilized in the IndiSeas project, ecosystems were classified as deteriorating if one or more indicators showed a declining trend. As will be discussed presently, it is important to understand all indicator trends, and the cause of these trends, in order to categorize the ecosystem because often declining trends do not indicate a negative effect on the ecosystem. This again highlights the importance of including advice from local/regional experts to ensure the correct interpretation of trends. The improvements made to the framework all act to ensure the correct interpretation and understanding of ecosystem level changes occurring in marine ecosystems, and ensure the correct categorization of the ecosystems considered.
Table 2. Comparison of methods employed in previous decision trees with the decision tree developed in this study.

\begin{tabular}{|c|c|}
\hline $\begin{array}{l}\text { Previous Decision Tree } \\
\text { Frameworks }\end{array}$ & Current Decision Tree Framework \\
\hline $\begin{array}{l}\text { Categories assigned to indicators: } \\
\text {-Improving; } \\
\text {-Not improving; } \\
\text {-Deteriorating; }\end{array}$ & $\begin{array}{l}\text { Categories assigned to indicators: } \\
\text {-Improving; } \\
\text {-Possibly improving; } \\
\text { - Neither improving nor } \\
\text { deteriorating; } \\
\text {-Possibly deteriorating; } \\
\text {-Deteriorating; }\end{array}$ \\
\hline Rule-based or fuzzy logic approach & Score-based approach \\
\hline Analysis of entire data sets & $\begin{array}{l}\text { Division of data sets into time } \\
\text { periods when appropriate. This } \\
\text { allows regime shifts to be accounted } \\
\text { for when analyzing indicator trends. }\end{array}$ \\
\hline $\begin{array}{l}\text { Assess the impact of fishing } \\
\text { pressure on indicators }\end{array}$ & $\begin{array}{l}\text { Assess the impacts of fishing } \\
\text { pressure and environmental } \\
\text { variability on indicators }\end{array}$ \\
\hline $\begin{array}{l}\text { Trends assessed through analysis of } \\
\text { data }\end{array}$ & $\begin{array}{l}\text { Inclusion of knowledge from } \\
\text { ecosystem experts when assessing } \\
\text { indicator trends }\end{array}$ \\
\hline $\begin{array}{l}\text { Possible redundancies of indicators } \\
\text { not identified }\end{array}$ & $\begin{array}{l}\text { Correlations conducted to identify } \\
\text { possible redundancies of indicators }\end{array}$ \\
\hline Analysis of ecosystem indicators & $\begin{array}{l}\text { Indicators separated into ecological } \\
\text { and fishing pressure indicators }\end{array}$ \\
\hline $\begin{array}{l}\text { Ecosystem classified as } \\
\text { deteriorating if one or more } \\
\text { indicators showed negative trend }\end{array}$ & $\begin{array}{l}\text { All indicator trends considered } \\
\text { before ecosystem is classified }\end{array}$ \\
\hline $\begin{array}{l}\text { Fishing and ecological indicators } \\
\text { not separated }\end{array}$ & $\begin{array}{l}\text { Fishing pressure indicators } \\
\text { combined into one indicator of } \\
\text { overall fishing pressure }\end{array}$ \\
\hline
\end{tabular}

The application of the framework to an ecosystem involves a multistep process summarized in Figure 1 (see Appendix 1 for an example of the application of the framework to the southern Benguela ecosystem). Following the flow in Figure 1, first data series are divided (where applicable) based on detected or documented environmental shifts, following which trends in indicators are analyzed. This step has proved particularly important in ecosystems such as the southern Benguela, where well-documented regime shifts (Blamey et al. 2012) that have occurred in the ecosystem mask trends in indicators if the data set is not divided. Although the methods used in detection of shift in the data differ between the case studies discussed below, we suggest that breakpoint analysis should be used to detect shifts.

Next, indicator trends were determined for the entire suite of indicators (fishing, environmental, and ecological), making use of linear regressions and ensuring that autocorrelation was accounted for. Although linear regressions are not the most sophisticated statistical method, an advantage of such an approach can be found in its simplicity, interpretability, and scientific acceptance. Following the detection of trends, the novel score-based approach that was developed was applied to indicators, with scores being attributed based on the direction and significance of observed trends. IndiSeas indicators have been formulated so that smaller indicator values will be observed under increased fishing pressure, and therefore the more negative trends detected, theoretically, the worse the state of the ecosystem. Based on this, the scoring system has been formulated so that lower 
scores are attributed to positive trends, i.e., "good trends," therefore, the higher the overall ecosystem score the worse the state of the ecosystem. However, it is important to note that negative trends in indicators are not always related to increased fishing pressure and can be linked to changes in environmental variability and management strategies, which were accounted for in our case-specific applications (see case studies below). This highlights the caution needed when interpreting and understanding indicator trends, as well as the need to include ecosystem experts at each step of framework application to ensure that results are correctly interpreted. Throughout the analyses, a wider range of significance levels than typical were considered important, with significance levels up to $10 \%$ included to account for interannual variability in a time series (Howard et al. 2007). These trends were recognized as "ecologically significant" (see Table 2).

To assess the impact of fishing pressure on ecosystems, the next step of the framework application entailed combing the fishing pressure indicators (see Lockerbie et al. 2016; Table 1) into an indicator of overall fishing pressure. It was necessary for the assimilation of these indicators into a single indicator to be ecosystem specific, depending on management and fishing activity in individual systems. In general, however, a $50 \%$ weighting was applied to inverse fishing pressure because this indicator represents the most direct impact of fishing pressure on the ecosystem and was highlighted as being particularly important by ecosystem experts. The remaining 50\% was spread equally among the remaining fishing indicators (landings, marine trophic index, trophic level of landings, and intrinsic vulnerability index).

Following the determination of fishing pressure and environmental indicator trends, it was necessary to account for the impacts of these drivers on the system, and therefore on ecological indicators. Experts were consulted and extensive literature explored to determine whether the observed trends in fishing pressure and/or environmental variability were the cause of trends observed in ecological indicators. To ensure that the influence of these drivers was captured in the framework, a score adjustment system was developed, modifying ecological indicator scores to reflect the influence of these drivers on the ecosystem (Fig. 2). The process of developing and implementing score adjustment systems involved multiple sensitivity analyses with considerable input from ecosystem experts (Lockerbie et al. 2016, Lockerbie et al. 2017a, b), ensuring that any weightings applied to indicators did not act to override or mask important trends in other indicators. Again, it was necessary for this step to be ecosystem specific.

It was also essential to account for potential redundancies of indicators included within the framework. A weighting system was employed, accounting for any potential redundancies, based on the work conducted in Coll et al. (2016). Coll et al. (2016) observed that correlated indicators may be somewhat redundant, therefore this step acted to reduce the contribution of significantly correlated, i.e., potentially redundant, indicators to the overall ecosystem score in order to ensure these indicators did not bias this score. Finally, after determining the mean indicator score, following the necessary adjustments and weightings, the ecosystem (or specific period of an ecosystem) could be classified according to its state (Table 3 ).
Fig. 2. Adjustment of original scores attributed to ecological indicators. Original scores were multiplied by the appropriate factor to give a new score, depending on the impact and trend of fishing pressure. The new score was then adjusted again by multiplying by the appropriate factor depending on whether environmental variability could influence this trend to give a final score (adjusted from Lockerbie et al. 2016).

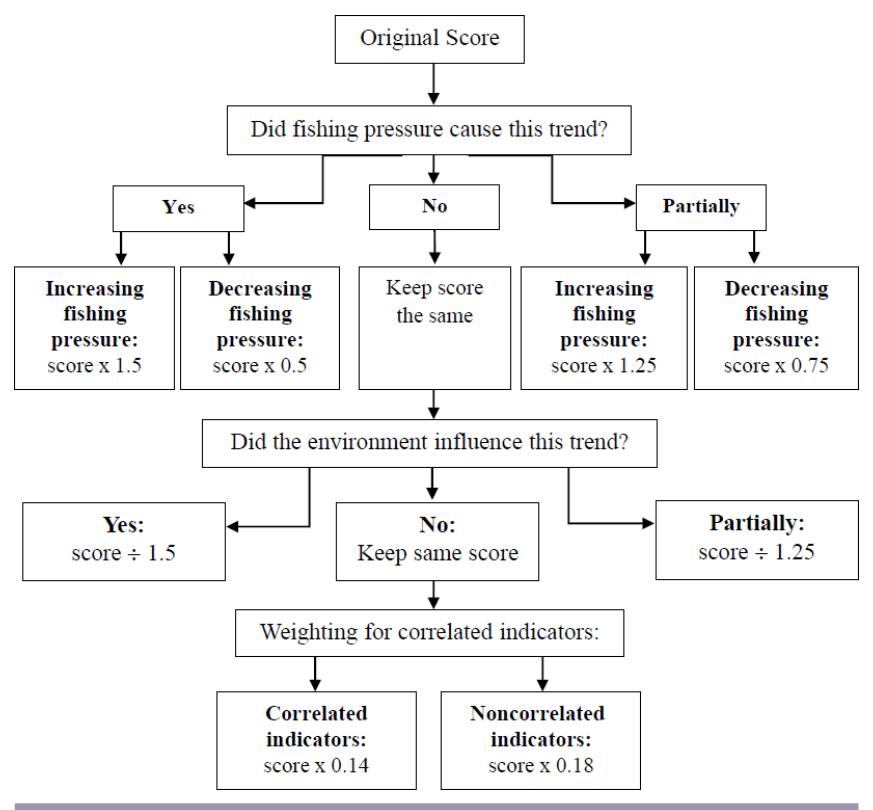

Table 3. Overall ecosystem scores (after application of weightings) and corresponding ecosystem categories of ecosystem classification (from Lockerbie et al. 2016).

\begin{tabular}{ll}
\hline \hline Overall Ecosystem Score & Categorization \\
\hline $1-1.49$ & Improving \\
$1.5-2.49$ & Possibly Improving \\
$2.5-3.49$ & No Improvement or Deterioration \\
$3.5-4.49$ & Possibly Deteriorating \\
$4.5-5$ & Deteriorating \\
\hline
\end{tabular}

Because the goal of developing such a framework was to allow comparative assessment of ecosystems, it was necessary to test the framework on multiple ecosystems. When selecting ecosystems, the decision was made to first apply the framework to ecosystems that showed some similarities because it was anticipated that the integrity of the framework was more likely to hold in ecosystems with similar dynamics. For this reason, after its primary application to the southern Benguela ecosystem, the framework was subsequently applied to the South Catalan Sea. Although located in very different geographical regions, these ecosystems have several similarities, including the influence of localized, wind-driven upwelling and the dominant role of small pelagic fish in both systems. However, in order to truly test the strength of the framework, it was also necessary to apply it to an ecosystem with substantial differences. Therefore, the North Sea was selected for the next case study, which although similar in terms of temperate climate and the inclusion of a continental 
shelf, has vastly different biological components and a complex history of exploitation.

It was also important to apply the framework to ecosystems that are already well understood. This ensured that ecosystem experts could confirm that the framework was successfully describing known ecosystem dynamics, and fully capturing changes known to have occurred within the ecosystem. Only once confident that the framework can successfully categorize ecosystems based on past data would it be possible to update data sets with the most recent data available and determine the state of the ecosystem under current conditions.

\section{RESULTS}

\section{Case studies}

The above-described framework has been applied to three ecosystems, the southern Benguela (Lockerbie et al. 2016), South Catalan Sea (Lockerbie et al. 2017a) and the North Sea (Lockerbie et al. 2017b). Although somewhat similar, these ecosystems have varying characteristics, exploitation histories, and management strategies. These case studies therefore provided an opportunity to test the framework across temperate and upwelling ecosystems, and shelf seas. Summaries of the application of the framework to each ecosystem are detailed below, with full descriptions found in the articles referenced above.

\section{Southern Benguela}

The framework was first developed for the southern Benguela ecosystem (SB) (Lockerbie et al. 2016). This ecosystem forms one of four eastern boundary upwelling ecosystems and is therefore considered one of the most productive marine ecosystems worldwide. The system undergoes wasp-waist control, with small pelagic fish providing dominant means of controlling energy flows between higher and lower trophic levels (Cury et al. 2000). However, when under no or moderate exploitation, high levels of primary production, resulting from upwelling favorable winds, leads to increases in zooplankton, small pelagic fish, and even top predators (Travers-Trolet et al. 2014). Travers-Trolet et al. (2014) observed that these high levels of primary production in the southern Benguela appear to reduce the propagation of the topdown effects of fishing pressure, therefore dampening the impacts of fishing on the lower trophic levels of the food web.

Blamey et al. (2012) detected regime shifts within the SB that influence both biological and physical components of the ecosystem, including changes in wind, upwelling, lobsters, urchins, and cormorant breeding pairs. These shifts, which were detected using three varying methods of time series analysis, were used to divide the data series into three distinct periods; Period 1 (1978-1993), Period 2 (1994-2003), and Period 3 (2004-2010). Upwelling, sea surface temperature, chlorophyll concentration, and the position of the South Atlantic High Pressure Cell were selected as environmental indicators.

Following analysis on indicator trends and adjustment of scores to account for the impacts of fishing, environmental variability, and correlated indicators (as described above), the ecosystem was classified as neither improving nor deteriorating over Periods 1 and 2, and possibly improving over Period 3 (Lockerbie et al. 2016). These classifications successfully reflect what is known to have occurred in the ecosystem over the periods assessed. For example, a significant but short-lived increase in small pelagic fish that arose in the early 2000s (Roy et al. 2001) was reflected in Period 2 by a significant decrease in mean lifespan and the proportion of predators, as well as an increase in the survey biomass. This was the first instance were the need to engage with ecosystem experts to avoid the misinterpretation of indicators trends was highlighted as crucial to ensure the correct interpretation of trends.

\section{South Catalan Sea}

The South Catalan Sea (SCS) ecosystem was selected as a second case study because of its similarities with the SB (Coll et al. 2006, Lockerbie et al. 2017a). The region has previously been categorized as 'highly impacted' (Coll et al. 2010), which is unsurprising considering the long history of fishing in the Mediterranean Sea.

In this case the ecosystem was divided into two periods, based on known atmospheric, hydrological, and ecological changes that occurred in the late 1980s (Conversi et al. 2010), as well as sensitivity analyses (Lockerbie et al. 2017a); Period 1 (1978-1990) and Period 2 (1991-2010). The same score adjustment and weighting system was employed as for the $\mathrm{SB}$, accounting for the influences of fishing pressure and environmental variability. Following analysis of the official data, the ecosystem was classified as neither improving nor deteriorating in Period 1 and possibly improving over Period 2. This did not align with what is known to have occurred in the ecosystem over these periods (see Coll et al. 2014a, b) because official data in the Mediterranean Sea do not currently consider the issue of illegal, unregulated, or unreported (IUU) catch. Therefore, indicator trends did not truly reflect what was happening in the ecosystem and it was therefore necessary to develop a way to account for IUU when applying the framework. This was aided by the work conducted by Coll et al. $(2014 a, b)$, which reconstructed official data to account for IUU catches. The availability of this information greatly facilitated the successful assessment of the ecosystem, and the adjustment of indicators to account for IUU catches was supported by ecosystem experts, as well as consideration of literature and local datasets. Following consultation with ecosystem experts, the decision was made to adjust the overall fishing pressure indicator score from an "ecologically significant decrease" to an "ecologically significant increase," to account for IUU. This was a conservative adjustment based on the exponential increase in removals that has been suggested by Coll et al. (2014b), and allowed indicator trends to more accurately reflect known ecosystem dynamics. Following these adjustments, the ecosystem was classified as possibly deteriorating over Period 1 and neither improving nor deteriorating over Period 2, reflecting what is known to have occurred within the ecosystem.

\section{North Sea}

The North Sea (NS) is one of the best studied and economically most important marine regions in the world. This system shares some similarities with the SB and SCS, such as the temperate climate and the continental shelf as a defining feature. However, the NS also provided an interesting contrast because of the dominance of different species and the lack of upwelling dynamics. The NS provided a challenging assessment considering the long history of overfishing and the subsequent implementation of effective management measures. This posed a 
fresh challenge when interpreting indicator trends because in some cases trends reflected the implementation of management rather than ecosystem change as a result of the influence of fishing or environmental variability. For example, the landings indicator showed a decreasing trend since 2003 which, according to the way that IndiSeas indicators are formulated, suggests a decrease in fish within the ecosystem. In contrast, inverse fishing pressure increased in the period 1983-2003 and then stabilized thereafter indicating positive change. Some stocks, such as cod (Gadus morhua), are currently recovering and increasing in biomass, yet catches are restricted to allow rebuilding. Other stocks, such as plaice (Pleuronectes platessa), have increased to their highest ever recorded levels, yet catches and fishing mortality have remained at comparable levels over the last decade to meet maximum sustainable yield targets. So, this trend toward lower landings is in part a result of improved management measures, which restricted quotas, rather than a decrease in overall fish biomass. During the period studied, there has been a similar decrease in fishing effort partly because of vessel decommissioning schemes, which was followed by signs of recovery in the size structure of the demersal fish community (Engelhard et al. 2015). Therefore, the negative trends in the landings indicator for all retained species were reconsidered as a positive change. Because the inverse fishing pressure indicator is limited by missing biomass data for some species (particularly invertebrates), the landings indicator received a higher weighting $(50 \%)$ than in previous applications when calculating the overall fishing pressure indicator because it likely better reflected wider ecosystem effects arising from fisheries. The considerable influence of historically high fishing pressure on higher trophic levels also limited the propagation of bottom-up influences through the food web (Lynam et al. 2017). Therefore, the influence of climatic drivers appeared to have been limited to lower trophic levels.

Despite these intricacies, the recognition that several indicator trends (particularly the pressure indicators) resulted from the influence of management measures, rather than ecosystem change, enabled trends to be interpreted correctly. This case study, by virtue of improved methodology implemented as the framework developed and progressed, adopted a different method to divide the data series into time periods then used in the SB and SCS. Breakpoint analysis was used to detect structural change points in the environmental data (Zeileis et al. 2002, Bai and Perron 2003). Based on the detected breakpoints, the data series was divided into three periods; Period 1 (1983-1992), Period 2 (1993-2003), and Period 3 (2004-2010). Following score adjustments and weighting (see Lockerbie et al. 2017b), the ecosystem was classified as neither improving nor deteriorating over Period 1, with Periods 2 and 3 being classified as possibly improving. This suggests that the ecosystem was moving out of its previously poor condition, likely linked to the stringent management methods being enforced. When analyzed as an entire data set, without the division into separate periods, relatively few significant indicator trends were observed. This suggests that the poor state of the ecosystem at the beginning of the time series masked the positive effects of the change in management observed in recent decades. This again highlights the need, in some cases, to divide data series into distinct time periods in order to truly understand changes occurring within the ecosystem.

\section{DISCUSSION}

\section{Evolution of the framework}

With the application of the framework to each ecosystem, adjustments and improvements were made. With the support and advice from ecosystem experts, the framework evolved through each application, developing into a more robust tool that should be applied in future assessments. Despite this evolution, there are further modifications that could further improve the framework, increasing its potential to be incorporated into current management strategies.

As it currently stands (and as is the case for every model), the framework is dependent on several assumptions that are made when it is applied to an ecosystem. For example, the overall ecosystem score relies heavily on decisions made throughout the application of the framework, such as the relative impacts of fishing and the environment on ecological indicators. This can be observed in the NS case study, where it has been suggested that the influence of management affected trends in pressure indicators and subsequent impacts on the ecosystem. Similarly, long-term change in the biomass of commercial fish stocks has been linked more strongly to fishing pressure such that environmental influences have been minimized (Lynam et al. 2017). Based on this knowledge, the decision was made to modify the influence of environmental variability to only partially explain observed indicator trends. However, this adjustment directly impacts the categorization of the ecosystem. By way of sensitivity analysis, it appears possible that the stringent management methods enforced in the more recent years of the data series could have entirely overshadowed the impact of the environment. If this was the case, following the assessment the ecosystem would have been scored as 2.75 and 2.66 in Periods 2 and 3, respectively, and would be classified as neither improving nor deteriorating over both periods. This highlights the importance of considering ecosystem dynamics across the full-time period and throughout the application of the framework. However, it is anticipated that the inclusion of expert knowledge throughout the assessment process reduces the possibility of wrongly classifying an ecosystem.

The use of linear regressions in detecting indicator trends could also benefit from re-evaluation. The strength of the framework could be augmented through the use of other statistical methods. Ecosystem responses to various drivers can be either linear or nonlinear, depending on the stressors considered and the interactions between stressors ( $\mathrm{Fu}$ et al. 2019b). If the responses are nonlinear, linear regressions may not give an accurate indication of trends. The division of the data series into periods, as in the above case studies, accounts to some extent for this nonlinearity, however, the framework might benefit from the use of reference points and threshold values for indicators. An ecosystem threshold can be identified as a large response or abrupt change in ecosystem state or function in response to a small change in an anthropogenic or environmental pressure (Groffman et al. 2006, Samhouri et al. 2017). Identifying these thresholds can help guide management actions and avoid undesirable shifts in ecosystem state (Foley et al. 2015).

Reference points for an indicator can be "target" reference points, for which the goal is to reach such a point, or "limit," or "precautionary" reference points, which are thresholds that 
should not be crossed (Samhouri et al. 2011, Levin et al. 2014). Typically, limit reference points would be considered more useful in terms of conservation of an ecosystem, while target reference points would be more suitable if the goal was to maximize yield (e.g., Hall and Mainprize 2004, Briton et al. 2019). In the past, reference points typically consisted of a value derived from expert opinion (Shin et al. 2010), a value estimated from presumed unexploited populations, or were determined through comparisons of a measured value relative to a long-term average of a time series (Levin et al. 2013, Tam et al. 2017). However, in recent years there has been significant progress in developing ecosystem-level reference points, particularly in North America (Large et al. 2015a, Samhouri et al. 2017, Tam et al. 2017). These reference points can be calculated for multiple marine ecosystems using thresholds from empirically derived ecological indicators (Large et al. 2015a, b, Link et al. 2012, 2015, Samhouri et al. 2017, Tam et al. 2017). There is therefore potential for more refined reference points and threshold values to be determined for the ecological indicators utilized in the IndiSeas project, which should enhance comparable assessments of ecosystem status across regions (Tam et al. 2017). However, again it is important to note that indicators that allow the assessment of human well-being are still underdeveloped (McShane et al. 2011, Howe et al. 2014, Yang et al. 2015), and advancement in these indicators would be necessary before we are able to (i) determine thresholds for societal needs, or (ii) to determine the trade-offs between human needs and conservation of marine resources (Dearing et al. 2014, DePiper et al. 2017, Tam et al. 2017).

\section{Incorporation of the framework into current management strategies}

Although marine systems function at scales ranging from molecules up through to social-ecological systems, it is important to recognize the relevance of examining changes at the ecosystem level. The use of ecosystem-level assessments has been acknowledged in current management methods being applied around the world (e.g., Halpern et al. 2012, ICES 2016, PICES 2016), where it is used in conjunction with single-species approaches to provide a more comprehensive understanding of changes occurring in marine ecosystems.

In terms of incorporating this framework into current management approaches, several issues will be faced within the South African context. Although an EAF working group did exist within the Department of Agriculture, Forestry and Fisheries, aimed at addressing the application of an EAF in South Africa, this working group was disbanded in 2014. Therefore, current management schemes do not operate more broadly than at the fishery (fleet) level. As it currently stands, South African fisheries management risks developing into "patchwork management" (Degnbol 2005), where the connections between separate issues are not considered, and links within a system are not required to be understood. Under such as approach, new regulations are developed ad hoc and according to the concerns and influences of various stakeholder groups (Degnbol 2005), potentially leading to inconsistencies within management. The current situation in South African fisheries management will need to undergo significant transformation before an EAF can be fully implemented. However, the application of a framework such as that discussed here allows the necessary science behind and EAF to be consolidated and interpreted, preparing for a time when broader, cross-cutting, ecosystem-level management comes into effect.

In some places, however, the application of ecosystem level management is further advanced. For example, the Common Fisheries Policy (CFP) that is implemented in the European Union (EU) underwent reform in 2002, moving toward the sustainable use of living resources from an environmental, economic, and social point of view. When this reform did not live up to expectations (EC 2010), with some stocks continuing to deteriorate, the CFP underwent further reform in 2013. This most recent reform represented a major move toward an ecosystembased fisheries management consistent with the Marine Strategy Framework Directive (MSFD, 2008/56/EC). The inclusion of an ecosystem-based approach to fisheries in the CFP is an important step toward the realization of implementing such management processes in European waters. This latest reform also acknowledged the need to regionalize management, taking into account the eight individual large marine ecosystems within Europe. This is in line with the approach described here, highlighting the importance of considering ecosystem-specific features and including ecosystem experts in order to fully comprehend ecosystem processes and changes, and implement successful system-based management.

Also within the Northern hemisphere, North America has progressed significantly toward the implementation of an EAF. Within the North American context, indicators have also been used to assess the state of marine ecosystems (Link 2005, Link et al. 2010, Samhouri et al. 2014, Large et al. 2015b). Although not the sole way in which progress has been made, indicators have been highlighted as essential in the implementation of IEAs in North America. This includes their use in assessing ecosystem trends, identifying the causes of observed trends and the monitoring of indicators to determine whether any actions taken are proving successful (Samhouri et al. 2014). The use of a stringently selected suite of indicators, such as those used here, incorporated into a designated framework could aid IEAs not only in the North American context, but globally because of the comparative nature of the framework.

Within the Mediterranean region, the General Fisheries Commission for the Mediterranean (GFCM) acts as a regional fisheries management organization. This commission currently comprises 24 members ( 23 member countries and the EU). Within this region, the dramatic ecosystem changes observed in the Black Sea have acted as evidence of the importance of accounting for multiple stressors in the management of fisheries, in line with an EAF (FAO 2016). Although an EAF is not currently implemented in the Mediterranean, the region is mentioned within the context of EU policies and goals toward achieving an EAF for Europe. The poor status of marine resources in the Mediterranean Sea highlights the urgent need to modify the current management methods in the region, both in European and non-European waters. The full application of the CFP and MSFD in EU member states may bring steps toward this direction and can benefit from the knowledge gained from integrated studies such as the one presented here.

Within the Southern hemisphere, Australia is also relatively advanced in implementing an ecosystem approach in its marine fisheries sector. The Australian Fisheries Management Authority 
(AFMA) makes use of an ecological risk management framework to assist decision makers. The goal of such frameworks is to ensure that fisheries management is consistent with the ecologically sustainable development objective desired by AFMA. Australia has adopted a wide variety of tools in order to implement an ecosystem approach, including end-to-end ecosystem models (e. g., Fulton et al. 2015), risk and cumulative impact assessments (e. g., Anthony et al. 2013), structured assessment processes, and marine spatial planning (Day 2002, Dunstan et al. 2016). Alongside this, a wide range of well-defined governance frameworks have been developed, ranging from national to regional and local scales (Smith et al. 2017). The recognition that both failures and successes observed in implementing ecosystem level management can be linked to the implementation of appropriate governance and institutional frameworks, rather than the science being used, has helped Australia move away from overarching approaches that are often too ambitious (Tallis et al. 2010, Smith et al. 2017). The development of a variety of frameworks, available at the relevant level for the ecosystem being considered, has aided the success in implementing an ecosystem approach that has been observed in Australia.

Although the framework discussed here cannot facilitate the implementation of an ecosystem approach in isolation, it could help in detecting the wider ecosystem implications of fishinginduced changes in biodiversity. Because detection of changes at the ecosystem level signifies that severe changes must be taking place at higher functional resolution, changes in ecosystem indicators such as those included in this framework may provide warnings of important changes that are happening, which would also influence the community and population levels.

\section{Global context}

The framework appears, thus far, to be capable of successfully categorizing multiple ecosystems. However, for the method to be valuable in the global context of fisheries management, its contribution to the various assessments currently being employed in assessing marine ecosystems must be considered. In recent decades a move toward integrated approaches based on collaborative scientific research has been recognized as necessary to better inform decision making (Sutherland et al. 2012). The multi-institutional collaborations involved in the IndiSeas project align nicely with such a goal. The use of indicators, the application of a methodology to multiple ecosystems, and the aim of synthesizing large amounts of information into easily communicable outputs are also aligned to methods currently being applied by fisheries scientists and managers around the world. Where indicators have found traction with policy makers, they have been involved throughout the development process of indicator-based assessment to ensure that implementation needs are met and continued engagement between policy makers and scientists is required to interpret and communicate assessment outcomes (McQuatters-Gollop et al. 2019).

Within European waters, the MSFD is aimed at determining criteria and methodological standards, to allow consistency in evaluation of the achievement of Good Environmental Status. As in the IndiSeas project, this process aims at applying an ecosystem approach to manage human activities and enable sustainable use of marine goods and services. The use of indicators in the framework discussed here corresponds well to multiple attributes desired by the MSFD (Table 4), particularly those aligning to the maintenance of biodiversity. This could allow the outputs of the framework to compliment the outputs of MSFD analyses, increasing the usefulness of the framework within the context of European ecosystems. Also in the northern hemisphere, integrated ecosystem assessments (IEAs), proposed by Levin et al. (2009), and adopted by the International Council for the Exploration of the Sea, have made an attempt to synthesize large amounts of scientific data. The framework discussed here had similar goals, synthesizing a comprehensive set of indicators at the level of ecosystem functioning into a meaningful assessment. However, although the inclusion of the human dimension is starting to be incorporated into IEAs (Fogarty 2014, Drakou et al. 2017), this step has only begun to be developed by IndiSeas (Bundy et al. 2017) and thus has not yet been incorporated into this framework.

Table 4. IndiSeas indicators and the corresponding attributes of the Marine Strategy Framework Directive (MSFD) for assessing good environmental status. Adjusted from MEECE (2011).

\begin{tabular}{|c|c|}
\hline IndiSeas Indicator & MSFD Attribute \\
\hline Mean Length & $\begin{array}{l}\text { Population condition, proportion of } \\
\text { selected species at the top of food } \\
\text { webs, population age, and size } \\
\text { distribution }\end{array}$ \\
\hline Mean Lifespan & $\begin{array}{l}\text { Population condition of key trophic } \\
\text { groups/species }\end{array}$ \\
\hline Survey Biomass & Population size \\
\hline Proportion of predatory fish & $\begin{array}{l}\text { Proportion of selected species at the } \\
\text { top of food webs, abundance of key } \\
\text { trophic groups, ecosystem structure }\end{array}$ \\
\hline Trophic level of the community & $\begin{array}{l}\text { Proportion of selected species at the } \\
\text { top of food webs, abundance of key } \\
\text { trophic groups }\end{array}$ \\
\hline Marine trophic index $(\mathrm{TL} \geq 3.25)$ & $\begin{array}{l}\text { Proportion of selected species at the } \\
\text { top of food webs }\end{array}$ \\
\hline Trophic level of landings & $\begin{array}{l}\text { Level of pressure of the fishing } \\
\text { activity (ecosystem level) }\end{array}$ \\
\hline Intrinsic vulnerability index & $\begin{array}{l}\text { Level of pressure of the fishing } \\
\text { activity }\end{array}$ \\
\hline Inverse fishing pressure & $\begin{array}{l}\text { Level of pressure of the fishing } \\
\text { activity }\end{array}$ \\
\hline
\end{tabular}

The framework presented here could also prove useful in the context of cumulative effect assessment (CEA) processes. Such assessments are considered holistic evaluations of the impacts of both human activities and natural processes on ecosystems, providing a specific form of IEAs (Jones 2016). These assessments could provide a powerful tool with which to manage and potentially reduce the cumulative impacts of anthropogenic activities on marine ecosystems (Duinker et al. 2013, Judd et al. 2015, Foley et al. 2017). However, despite the serious need for operational CEAs in marine ecosystem, this successful implementation of such assessments has remained a challenge. A wide range of frameworks have been developed to assess cumulative effects on marine ecosystems. Yet this abundance of approaches has resulted in variations in research agendas for CEAs has made it increasingly difficult to compare results from various ecosystems (Stock and Micheli 2016). This decision tree framework allows the assessment of the impacts of both fishing pressure and environmental variability on multiple ecosystems. 
Therefore, it could potentially provide a broadly applicable methodology, which is currently considered lacking within CEAs (Stelzenmüller et al. 2018). In Australia cumulative impact assessments have been used in numerous governance frameworks to assist with the implementation of ecosystem-based management, however, preliminary applications of existing risk assessment tools to ecosystems have been observed to potentially underestimate risk by up to $90 \%$ (Smith et al. 2017; Fulton unpublished data). Therefore, a new risk assessment tool that is able to address multisector interactions will be needed for application to marine ecosystem assessments.

\section{The future of the framework}

The greater number of ecosystems included in the approach, the stronger the comparative analysis would be (Shin and Shannon 2010). This framework could, consequently, be further strengthened through its application to a wider range of ecosystems, including those of varying type, size, and undergoing differing levels of influence from fishing pressure and climate variability. Therefore, it will be pragmatic to apply the framework to systems that differ greatly from those already considered, thereby increasing our understanding of how differences feed through the chosen set of indicators, and their combined evaluation in decision trees.

Possibly the most important next step in utilizing the framework will be the discussion of its use with relevant fisheries managers and stakeholders. The framework provides a tool with which to summarize large amounts of scientific information, which is the first step in successful communication of the knowledge gained from ecosystem assessments. Tools such as this can only be considered useful if stakeholders are responsive to the information being presented (Johnson and Chess 2006, Turnhout et al. 2007). Therefore, although the framework appears to have been successful thus far, its true practicality cannot be determined until it has been discussed with the appropriate audiences. This process could also include the development of social and economic indicators, which could be added to the framework and allow a more comprehensive assessment of the social-ecological system. The inclusion of such indicators could further align the framework with the desired outcomes of an EAF.

Finally, the framework could potentially be used to explore ecosystem well-being into the future. The nature of the framework supports its potential for predicting the state of marine ecosystems under potential future fishing and climate scenarios. The similarities of this framework to work such as, for example, envisaged by PICES FUTURE, could allow its use in synthesizing a subset of ecological indicators generated as outputs from forecasting runs of ecosystem models. Outputs from models such as Ecopath with Ecosim (Walters et al. 2000, Christensen and Walters 2004), Osmose (Shin and Cury 2004, Travers et al. 2009), or Atlantis (Fulton et al. 2005), could be synthesized in this way, and allow the evaluation of management strategies in the medium and long term. Therefore, it may be possible, using ecosystem models that are dynamic in time and even space, to learn from past ecosystem trajectories and driver histories to explore future scenarios of climate and fishing pressure, using a set of ecosystem indicators that have proven meaningful globally (e.g., Shin et al. 2018) and the synthetic framework presented here. A first attempt of assessing possible future scenarios for marine ecosystems, using a modified version of the framework discussed here, has now been made (Lockerbie and Shannon 2019).

\section{CONCLUSIONS}

Under current levels of fishing pressure, the development of successful management approaches is becoming increasingly important to preserve ecosystem services and food security for future generations. Alongside this, given the current rate of climate change, it is vital to consider the impacts on environmental variability and change alongside the impacts of fishing pressure. The framework considered here, tested on three case studies so far, has the potential to categorize marine ecosystems globally, considering how ecosystem impacts of fisheries can be influenced by environmental conditions. The success that the framework has accomplished thus far confirms the potential of comparative approaches for decision making within multiple marine ecosystems, and also underlines the necessity to include regional ecosystem expertise. As a next step, stakeholders need to be involved in the improved communication of this approach.

Alongside this, while ecological and environmental indicators support understanding of overarching patterns occurring within ecosystems, socioeconomic indicators are needed to help track patterns of human vulnerability and well-being (Tam et al. 2019). This can aid the understanding of the complexity of the human dimensions of an EAF (Bowen and Riley 2003, Pollnac et al. 2015, Colburn et al. 2016, Auad et al. 2018). Yet despite widespread acknowledgment of the need to consider socioeconomics when implementing an EAF, human dimensions are currently rarely considered in management scenarios. Some progress has been made, however, with social and economic indicators now being used to identify human communities vulnerable to both fishing collapses and climate change (Pollnac et al. 2015, Colburn et al. 2016), as well as assessing the well-being of these communities (Colburn et al. 2016, Bundy et al. 2017, Auad et al. 2018).

A suite of socioeconomic indicators could be encompassed into this framework, helping capture the cumulative influences of fishing, environmental variability, and coastal communities on ecosystems when informing management scenarios. This will enable fisheries managers and stakeholders not only to avoid ecological regime shifts, but also undesirable shifts to human coastal communities (Tam et al. 2019), providing a more holistic approach to decision making. Following some further improvements and adjustments, it is possible that this framework could be used to synthesize large amounts of information about the states and trends of marine ecosystems, in a globally comparative way.

Responses to this article can be read online at: http://www.ecologyandsociety.org/issues/responses. php/11508

\section{Acknowledgments:}

This study was funded by the South African Scientific Research Chair Initiative, of the Department of Science and Technology and administered by the National Research Foundation (NRF), through the chair in Marine Ecology and Fisheries. C.L. was supported by 
the Department for Environment, Food \& Rural Affairs of the UK (project MF1228 "Physics to Fisheries"). M.C. was supported by the Spanish Ministry of Economy, Industry and Competitively through the project PELWEB (I+D+I 2018-2020).

\section{Data Availability Statement:}

The datalcode that support the findings of this study are available on request from the corresponding author, [E.M.L.]. The datalcode are not publicly available because of ongoing research.

\section{LITERATURE CITED}

Anthony, K. R., J. M. Dambacher, T. Walshe, and R. Beeden. 2013. A framework for understanding cumulative impacts, supporting environmental decisions and informing resilience based management of the Great Barrier Reef World Heritage Area. Australian Institute of Marine Science, Townsville, Australia; CSIRO, Hobart, Australia; NERP Decisions Hub, University of Melbourne, Australia; and Great Barrier Reef Marine Park Authority, Townsville, Australia.

Anticamara, J. A., R. Watson, A. Gelchu, and D. Pauly. 2011. Global fishing effort (1950-2010): trends, gaps, and implications. Fisheries Research 107:131-136. https://doi.org/10.1016/j.

fishres.2010.10.016

Auad, G., J. Blythe, K. Coffman, and B. D. Fath. 2018. A dynamic management framework for socio-ecological system stewardship: a case study for the United States Bureau of Ocean Energy Management. Journal of Environmental Management 225:32-45. https://doi.org/10.1016/j.jenvman.2018.07.078

Bai, J., and P. Perron. 2003. Computation and analysis of multiple structural change models. Journal of Applied Econometrics 18:1-22. https://doi.org/10.1002/jae.659

Bastardie, F., J. R. Nielsen, B. S. Andersen, and O. R. Eigaard. 2013. Integrating individual trip planning in energy efficiency: building decision tree models for Danish fisheries. Fisheries Research 143:119-130. https://doi.org/10.1016/j.fishres.2013.01.018

Blamey, L. K., J. A. E. Howard, J. Agenbag, and A. Jarre. 2012. Regime-shifts in the southern Benguela shelf and inshore region. Progress in Oceanography 106:80-95. https://doi.org/10.1016/j. pocean.2012.07.001

Bowen, R. E., and C. Riley. 2003. Socio-economic indicators and integrated coastal management. Ocean \& Coastal Management 46:299-312. https://doi.org/10.1016/S0964-5691(03)00008-5

Briton, F., L. Shannon, N. Barrier, P. Verley, and Y.-J. Shin. 2019. Reference levels of ecosystem indicators at multispecies maximum sustainable yield. ICES Journal of Marine Science 76:2070-2081. https://doi.org/10.1093/icesjms/fsz104

Bundy, A., R. Chuenpagdee, J. L. Boldt, M. de Fatima Borges, M. L. Camara, M. Coll, I. Diallo, C. Fox, E. A. Fulton, A. Gazihan, et al. 2017. Strong fisheries management and governance positively impact ecosystem status. Fish and Fisheries 18:412-439. https://doi.org/10.1111/faf.12184

Bundy, A., M. Coll, L. J. Shannon, and Y.-J. Shin. 2012. Global assessments of the status of marine exploited ecosystems and their management: what more is needed? Current Opinion in
Environmental Sustainability 4:292-299. https://doi.org/10.1016/ j.cosust.2012.05.003

Bundy, A., L. J. Shannon, M.-J. Rochet, S. Neira, Y.-J. Shin, L. Hill, and K. Aydin. 2010. The good(ish), the bad, and the ugly: a tripartite classification of ecosystem trends. ICES Journal of Marine Science 67:745-768. https://doi.org/10.1093/icesjms/ $\underline{\text { fsp283 }}$

Cheung, W. W. L., R. Watson, T. Morato, T. J. Pitcher, and D. Pauly. 2007. Intrinsic vulnerability in the global fish catch. Marine Ecological Progress Series 333:1-12. https://doi.org/10.3354/ meps333001

Christensen, V., and C. J. Walters. 2004. Ecopath with ecosim: methods, capabilities and limitations. Ecological Modelling 172:109-139. https://doi.org/10.1016/j.ecolmodel.2003.09.003

Colburn, L. L., M. Jepson, C. Weng, T. Seara, J. Weiss, and J. A. Hare. 2016. Indicators of climate change and social vulnerability in fishing dependent communities along the Eastern and Gulf Coasts of the United States. Marine Policy 74:323-333. https:// doi.org/10.1016/j.marpol.2016.04.030

Coll, M., M. Carreras, C. Ciércoles, M.-J. Cornax, G. Gorelli, E. Morote, and R. Sáez. 2014a. Assessing fishing and marine biodiversity changes using fishers' perceptions: the Spanish Mediterranean and Gulf of Cadiz case study. PLOS ONE 9: e85670. https://doi.org/10.1371/journal.pone.0085670

Coll, M., M. Carreras, M. J. Cornax, E. Massutí, E. Morote, X. Pastor, A. Quetglas, R. Sáez, L. Silva, I. Sobrino, et al. $2014 b$. Closer to reality: reconstructing total removals in mixed fisheries from Southern Europe. Fisheries Research 154:179-194. https:// doi.org/10.1016/j.fishres.2014.01.013

Coll, M., L. J. Shannon, K. M. Kleisner, M. J. Juan-Jordá, A. Bundy, A. G. Akoglu, D. Banaru, J. L. Boldt, M. F. Borges, A. Cook, et al. 2016. Ecological indicators to capture the effects of fishing on biodiversity and conservation status of marine ecosystems. Ecological Indicators 60:947-962. https://doi. org/10.1016/j.ecolind.2015.08.048

Coll, M., L. J. Shannon, C. L. Moloney, I. Palomera, and S. Tudela. 2006. Comparing trophic flows and fishing impacts of a NW Mediterranean ecosystem with coastal upwelling systems by means of standardized models and indicators. Ecological Modelling 198:53-70. https://doi.org/10.1016/j.ecolmodel.2006.04.009

Coll, M., L. J. Shannon, D. Yemane, J. S. Link, H. Ojaveer, S. Neira, D. Jouffre, P. Labrosse, J. J. Heymans, E. A. Fulton, and Y.-J. Shin. 2010. Ranking the ecological relative status of exploited marine ecosystems. ICES Journal of Marine Science 67:769-786. https://doi.org/10.1093/icesjms/fsp261

Conversi, A., S. F. Umani, T. Peluso, J. C. Molinero, A. Santojanni, and M. Edwards. 2010. The Mediterranean Sea regime shift at the end of the 1980s, and intriguing parallelisms with other European basins. PLoS ONE 5:e10633. https://doi. org/10.1371/journal.pone.0010633

Cury, P., A. Bakun, R. J. M. Crawford, A. Jarre, R. A. Quiñones, L. J. Shannon, and H. M. Verheye. 2000. Small pelagics in upwelling systems: patterns of interaction and structural changes in "wasp-waist" ecosystems. ICES Journal of Marine Science 57:603-618. https://doi.org/10.1006/jmsc.2000.0712 
Cury, P. M., C. Mullon, S. M. Garcia, and L. J. Shannon. 2005. Viability theory for an ecosystem approach to fisheries. ICES journal of Marine Science 62:577-584. https://doi.org/10.1016/j. icesjms.2004.10.007

Daskalov, G. M., A. N. Grishin, S. Rodionov, and V. Mihneva. 2007. Trophic cascades triggered by overfishing reveal possible mechanisms of ecosystem regime shifts. Proceedings of the National Academy of Sciences of the USA 104:10518-10523. https://doi.org/10.1073/pnas.0701100104

Day, J. C. 2002. Zoning-lessons from the Great Barrier Reef marine park. Ocean \& Coastal Management 45:139-156. https:// doi.org/10.1016/S0964-5691(02)00052-2

Dearing, J. A., R. Wang, K. Zhang, J. G. Dyke, H. Haberl, M. S. Hossain, P. G. Langdon, T. M. Lenton, K. Raworth, S. Brown, et al. 2014. Safe and just operating spaces for regional socialecological systems. Global Environmental Change 28:227-238. https://doi.org/10.1016/j.gloenvcha.2014.06.012

Degnbol, P. 2005. Indicators as a means of communicating knowledge. ICES Journal of Marine Science 62:606-611. https:// doi.org/10.1016/j.icesjms.2004.12.007

DePiper, G. S., S. K. Gaichas, S. M. Lucey, P. Pinto da Silva, M. R. Anderson, H. Breeze, A. Bundy, P. M. Clay, G. Fay, R. J. Gamble, et al. 2017. Operationalizing integrated ecosystem assessments within a multidisciplinary team: lessons learned from a worked example. ICES Journal of Marine Science 74:2076-2086. https://doi.org/10.1093/icesjms/fsx038

Drakou, E. G., C. Kermagoret, A. Comte, B. Trapman, and J. C. Rice. 2017. Shaping the future of marine socio-ecological systems research: when early-career researchers meet the seniors. ICES Journal of Marine Science 74:1957-1964. https://doi.org/10.1093/ icesjms/fsx009

Duinker, P. N., E. L. Burbidge, S. R. Boardley, and L. A. Greig. 2013. Scientific dimensions of cumulative effects assessment: toward improvements in guidance for practice. Environmental Reviews 21:40-52. https://doi.org/10.1139/er-2012-0035

Dunstan, P. K., N. J. Bax, J. M. Dambacher, K. R. Hayes, P. T. Hedge, D. C. Smith, and A. D. Smith. 2016. Using ecologically or biologically significant marine areas (EBSAs) to implement marine spatial planning. Ocean \& Coastal Management 121:116-127. https://doi.org/10.1016/j.ocecoaman.2015.11.021

Engelhard, G. H., C. P. Lynam, B. García-Carreras, P. J. Dolder, and S. Mackinson. 2015. Effort reduction and the large fish indicator: spatial trends reveal positive impacts of recent European fleet reduction schemes. Environmental Conservation 42:227-236. https://doi.org/10.1017/S0376892915000077

European Commission (EC). 2010. Commission decision of 1 September 2010 on criteria and methodological standards on good environmental status of marine waters. Official Journal of the European Union L232, 14e24.

Fogarty, M. J. 2014. The art of ecosystem-based fishery management. Canadian Journal of Fisheries and Aquatic Sciences 71:479-490. https://doi.org/10.1139/cjfas-2013-0203

Foley, M. M., R. G. Martone, M. D. Fox, C. V. Kappel, L. A. Mease, A. L. Erickson, B. S. Halpern, K. A. Selkoe, P. Taylor, and
C. Scarborough. 2015. Using ecological thresholds to inform resource management: current options and future possibilities. Frontiers in Marine Science 2:95. https://doi.org/10.3389/ fmars.2015.00095

Foley, M. M., L. A. Mease, R. G. Martone, E. E. Prahler, T. H. Morrison, C. C. Murray, and D. Wojcik. 2017. The challenges and opportunities in cumulative effects assessment. Environmental Impact Assessment Review 62:122-134. https://doi.org/10.1016/j. eiar.2016.06.008

Food and Agriculture Organization (FAO). 2002. Report of the expert consultation on catalysing the transition away from overcapacity in marine capture fisheries. FAO, Rome, Italy.

Food and Agriculture Organization (FAO). 2003. The ecosystem approach to fisheries, Food and Agriculture Organization of the United Nations technical guidelines for responsible fisheries nos 4 and 2. FAO, Rome, Italy.

Food and Agriculture Organization (FAO). 2004. The state of world fisheries and aquaculture. FAO, Rome, Italy.

Food and Agriculture Organization (FAO). 2016. The state of Mediterranean and Black Sea fisheries. FAO, Rome, Italy.

Food and Agriculture Organization (FAO). 2018. The state of world fisheries and aquaculture 2018-meeting the sustainable development goals. FAO, Rome, Italy.

Frank, K. T., B. Petrie, N. L. Shackell, and J. S. Choi. 2006. Reconciling differences in trophic control in mid-latitude marine ecosystems. Ecology Letters 9:1096-1105. https://doi.org/10.1111/ j.1461-0248.2006.00961.X

Fu, C., S. Large, B. Knight, A. J. Richardson, A. Bundy, G. Reygondeau, J. Boldt, G. I. Van Der Meeren, M. A. Torres, I. Sobrino, et al. 2015. Relationships among fisheries exploitation, environmental conditions, and ecological indicators across a series of marine ecosystems. Journal of Marine Systems 148:101-111. https://doi.org/10.1016/j.jmarsys.2015.01.004

Fu, C., Y. Xu, A. Bundy, A. Grüss, M. Coll, J. J. Heymans, E. A. Fulton, L. Shannon, G. Halouani, L. Velez, et al. 2019a. Making ecological indicators management ready: assessing the specificity, sensitivity, and threshold response of ecological indicators. Ecological Indicators 105:16-28. https://doi.org/10.1016/j. ecolind.2019.05.055

Fu, C., Y. Xu, A. Grüss, A. Bundy, L. Shannon, J. J. Heymans, G. Halouani, E. Akoglu, C. P. Lynam, and M. Coll. $2019 b$. Responses of ecological indicators to fishing pressure under environmental change: exploring non-linearity and thresholds. ICES Journal of Marine Science fsz182. https://doi.org/10.1093/ icesjms/fsz182

Fulton, E. A., F. Boschetti, M. Sporcic, T. Jones, L. R. Little, J. M. Dambacher, R. Gray, R. Scott, and R. Gorton. 2015. A multimodel approach to engaging stakeholder and modellers in complex environmental problems. Environmental Science \& Policy 48:44-56. https://doi.org/10.1016/j.envsci.2014.12.006

Fulton, E. A., A. D. Smith, and A. E. Punt. 2005. Which ecological indicators can robustly detect effects of fishing? ICES Journal of Marine Science 62:540-551. https://doi.org/10.1016/j.icesjms.2004.12.012 
Groffman, P. M., J. S. Baron, T. Blett, A. J. Gold, I. Goodman, L. H. Gunderson, B. M. Levinson, M. A. Palmer, H. W. Paerl, G. D. Peterson, et al. 2006. Ecological thresholds: the key to successful environmental management or an important concept with no practical application? Ecosystems 9:1-13. https://doi. org/10.1007/s10021-003-0142-Z

Hall, S. J., and B. Mainprize. 2004. Towards ecosystem-based fisheries management. Fish and Fisheries 5:1-20. https://doi. org/10.1111/j.1467-2960.2004.00133.x

Halpern, B. S., C. Longo, D. Hardy, K. L. McLeod, J. F. Samhouri, S. K. Katona, K. Kleisner, S. E. Lester, J. O'leary, M. Ranelletti, et al. 2012. An index to assess the health and benefits of the global ocean. Nature 488:615-620. https://doi.org/10.1038/nature11397

Heymans, J. J., and M. T. Tomczak. 2016. Regime shifts in the Northern Benguela ecosystem: challenges for management. Ecological Modelling 331:151-159. https://doi.org/10.1016/j. ecolmodel.2015.10.027

Howard, J. A. E., A. Jarre, A. E. Clark, and C. L. Moloney. 2007. Application of the sequential t-test algorithm for analysing regime shifts to the southern Benguela ecosystem. African Journal of Marine Science 29:437-451. https://doi.org/10.2989/

AJMS.2007.29.3.11.341

Howe, C., H. Suich, B. Vira, and G. M. Mace. 2014. Creating winwins from trade-offs? Ecosystem services for human well-being: a meta-analysis of ecosystem service trade-offs and synergies in the real world. Global Environmental Change 28:263-275. https:// doi.org/10.1016/j.gloenvcha.2014.07.005

International Council for the Exploration of the Sea (ICES). 2016. ICES Ecosystem overviews: Greater North Sea ecoregion. ICES Advice 2016 Book 6.

Jarre, A., B. Paterson, C. L. Moloney, D. C. Miller, J. G. Field, and A. M. Starfield. 2008. Knowledge-based systems as decision support tools in an ecosystem approach to fisheries: comparing a fuzzy-logic and a rule-based approach. Progress in Oceanography 79:390-400. https://doi.org/10.1016/j.pocean.2008.10.010

Jennings, S., S. Greenstreet, L. Hill, G. Piet, J. Pinnegar, and K. J. Warr. 2002. Long-term trends in the trophic structure of the North Sea fish community: evidence from stable-isotope analysis, size-spectra and community metrics. Marine Biology 141:1085-1097. https://doi.org/10.1007/s00227-002-0905-7

Jepson, M., and L. L. Colburn. 2013. Development of social indicators of fishing community vulnerability and resilience in the U.S. southeast and northeast regions. NOAA Technical Memorandum NMFS-F/SPO-129. U.S. Department of Commerce, National Oceanic and Atmospheric Administration, Silver Spring, Maryland, USA.

Johnson, B. B., and C. Chess. 2006. Evaluating public responses to environmental trend indicators. Science Communication 28:64-92. https://doi.org/10.1177/1075547006291346

Jones, F. C. 2016. Cumulative effects assessment: theoretical underpinnings and big problems. Environmental Reviews 24:187-204. https://doi.org/10.1139/er-2015-0073

Judd, A. D., T. Backhaus, and F. Goodsir. 2015. An effective set of principles for practical implementation of marine cumulative effects assessment. Environmental Science \& Policy 54:254-262. https://doi.org/10.1016/j.envsci.2015.07.008

Large, S. I., G. Fay, K. D. Friedland, and J. S. Link. 2013. Defining trends and thresholds in responses of ecological indicators to fishing and environmental pressures. ICES Journal of Marine Science 70:755-767. https://doi.org/10.1093/icesjms/fst067

Large, S. I., G. Fay, K. D. Friedland, and J. S. Link. 2015a. Critical points in ecosystem responses to fishing and environmental pressures. Marine Ecology Progress Series 521:1-17. https://doi. org/10.3354/meps 11165

Large, S. I., G. Fay, K. D. Friedland, and J. S. Link. $2015 b$. Quantifying patterns of change in marine ecosystem response to multiple pressures. PLoS ONE 10:e0119922. https://doi. org/10.1371/journal.pone.0119922

Levin, P. S., M. J. Fogarty, S. A. Murawski, and D. Fluharty. 2009. Integrated ecosystem assessments: developing the scientific basis for ecosystem-based management of the ocean. PLoS Biology 7: e1000014. https://doi.org/10.1371/journal.pbio.1000014

Levin, P. S., C. R. Kelble, R. L. Shuford, C. Ainsworth, Y. deReynier, R. Dunsmore, M. J. Fogarty, K. Holsman, E. A. Howell, M. E. Monaco, et al. 2013. Guidance for implementation of integrated ecosystem assessments: a U.S. perspective. ICES Journal of Marine Science 71:1198-1204. https://doi.org/10.1093/ icesims/fst112

Levin, P. S., C. R. Kelble, R. L. Shuford, C. Ainsworth, Y. deReynier, R. Dunsmore, M. J. Fogarty, K. Holsman, E. A. Howell, M. E. Monaco, S. A. Oakes, and F. Werner. 2014. Guidance for implementation of integrated ecosystem assessments: a U.S. perspective. ICES Journal of Marine Science 71:1198-1204. https://doi.org/10.1093/icesjms/fst112

Link, J. S. 2005. Translating ecosystem indicators into decision criteria. ICES Journal of Marine Science 62:569-576. https://doi. org/10.1016/j.icesjms.2004.12.015

Link, J. S., S. Gaichas, T. J. Miller, T. Essington, A. Bundy, J. Boldt, K. F. Drinkwater, and E. Moksness. 2012. Synthesizing lessons learned from comparing fisheries production in 13 northern hemisphere ecosystems: emergent fundamental features. Marine Ecology Progress Series 459:293-302. https://doi. org/10.3354/meps09829

Link, J. S., F. Pranovi, S. Libralato, M. Coll, V. Christensen, C. Solidoro, and E. A. Fulton. 2015. Emergent properties delineate marine ecosystem perturbation and recovery. Trends in Ecology \& Evolution 30:649-661. https://doi.org/10.1016/j.tree.2015.08.011

Link, J. S., D. Yemane, L. J. Shannon, M. Coll, Y.-J. Shin, L. Hill, and M. de Fatima Borges. 2010. Relating marine ecosystem indicators to fishing and environmental drivers: an elucidation of contrasting responses. ICES Journal of Marine Science 67:787-795. https://doi.org/10.1093/icesjms/fsp258

Lockerbie, E., M. Coll, L. J. Shannon, and A. Jarre. 2017a. The use of indicators for decision support in northwestern Mediterranean Sea fisheries. Journal of Marine Systems 174:64-77. https://doi.org/10.1016/j.jmarsys.2017.04.003

Lockerbie, E. M., C. P. Lynam, L. J. Shannon, and A. Jarre. $2017 b$. Applying a decision tree framework in support of an ecosystem 
approach to fisheries: IndiSeas indicators in the North Sea. ICES Journal of Marine Science 75:1009-1020. https://doi.org/10.1093/ icesjms/fsx215

Lockerbie, E. M., and L. Shannon. 2019. Toward exploring possible future states of the southern Benguela. Frontiers in Marine Science 6:380. https://doi.org/10.3389/fmars.2019.00380

Lockerbie, E. M., L. J. Shannon, and A. Jarre. 2016. The use of ecological, fishing and environmental indicators in support of decision making in southern Benguela fisheries. Ecological Indicators 69:473-487. https://doi.org/10.1016/j.ecolind.2016.04.035

Lynam, C. P., M. Llope, C. Möllmann, P. Helaouët, G. A. BaylissBrown, and N. C. Stenseth. 2017. Interaction between top-down and bottom-up control in marine food webs. Proceedings of the National Academy of Sciences 114:1952-1957. https://doi. org/10.1073/pnas.1621037114

Mardle, S., and S. Pascoe. 1999. A review of applications of multiple-criteria decision-making techniques to fisheries. Marine Resource Economics 14:41-63. https://doi.org/10.1086/mre.14.1.42629251

McQuatters-Gollop, A., I. Mitchell, C. Vina-Herbon, J. Bedford, P. F. E. Addison, C. P. Lynam, P. N. Geetha, E. A. Vermeulen, K. Smith, D. T. I. Bayley, E. Morris-Webb, H. J. Niner, and S. A. Otto. 2019. From science to evidence-how biodiversity indicators can be used for effective marine conservation policy and management. Frontiers in Marine Science 6:109. https://doi. org/10.3389/fmars.2019.00109

McShane, T. O., P. D. Hirsch, T. C. Trung, A. N. Songorwa, A. Kinzig, B. Monteferri, D. Mutekanga, H. Van Thang, J. L. Dammert, M. Pulgar-Vidal, et al. 2011. Hard choices: making trade-offs between biodiversity conservation and human wellbeing. Biological Conservation 144:966-972. https://doi. org/10.1016/j.biocon.2010.04.038

Megrey, B. A., J. S. Link, G. L. Hunt Jr, and E. Moksness. 2009. Comparative marine ecosystem analysis: applications, opportunities, and lessons learned. Progress in Oceanography 81:2-9. https://doi. org/10.1016/j.pocean.2009.04.002

Pauli, G. 2010. The blue economy: 10 years, 100 innovations, 100 million jobs. Paradigm, Taos, New Mexico, USA.

PICES (North Pacific Marine Science Organization). 2016. FUTURE Phase II Implementation Plan Term 2016-2020: FUTURE Science Program. PICES, Sidney, British Columbia, Canada.

Pickitch, E. K., C. Santora, E. A. Babcock, A. Bakun, R. Bonfil, D. O. Conover, P. Dayton, P. Doukakis, D. Fluharty, B. Heneman, E. D. Houde, J. Link, P. A. Livingstone, M. Mangel, M. K. McAllister, J. Pope, and K. J. Sainsbury. 2004. Ecosystem-based fishery management. Science 305:346-347. https://doi.org/10.1126/ science. 1098222

Pitcher, T., D. Kalikoski, and G. Pramod. 2006. Evaluations of compliance with the FAO (UN) Code of Conduct for Responsible Fisheries. Research Report Vol. 14, no. 2. Fisheries Centre, University of British Columbia, Vancouver, British Columbia, Canada.

Pollnac, R. B., T. Seara, and L. L. Colburn. 2015. Aspects of fishery management, job satisfaction, and well-being among commercial fishermen in the northeast region of the United States. Society \& Natural Resources 28:75-92. https://doi. org/10.1080/08941920.2014.933924

Rochet, M.-J., and V. M. Trenkel. 2003. Which community indicators can measure the impact of fishing? A review and proposals. Canadian Journal of Fisheries and Aquatic Sciences 60:86-99. https://doi.org/10.1139/f02-164

Rochet, M.-J., V. Trenkel, R. Bellail, F. Coppin, O. Le Pape, J.-C. Mahé, J. Morin, J.-C. Poulard, I. Schlaich, and A. Souplet. 2005. Combining indicator trends to assess ongoing changes in exploited fish communities: diagnostic of communities off the coasts of France. ICES Journal of marine Science 62:1647-1664. https://doi.org/10.1016/j.icesjms.2005.06.009

Roy, C., S. J. Weeks, M. Rouault, C. S. Nelson, R. G. Barlow, and C. D. van Der Lingen. 2001. Extreme oceanographic events recorded in the southern Benguela during the 1999-2000 summer season. South African Journal of Marine Science 97:465-471.

Sala, E. 2006. Top predators provide insurance against climate change. Trends in Ecology \& Evolution 21:479-480. https://doi. org/10.1016/j.tree.2006.07.006

Samhouri, J. F., K. S. Andrews, G. Fay, C. J. Harvey, E. L. Hazen, S. M. Hennessey, K. Holsman, M. E. Hunsicker, S. I. Large, K. N. Marshall, et al. 2017. Defining ecosystem thresholds for human activities and environmental pressures in the California Current. Ecosphere 8:e01860. https://doi.org/10.1002/ecs2.1860

Samhouri, J. F., A. J. Haupt, P. S. Levin, J. S. Link, and R. Shuford. 2014. Lessons learned from developing integrated ecosystem assessments to inform marine ecosystem-based management in the USA. ICES Journal of Marine Science 71:1205-1215. https:// doi.org/10.1093/icesjms/fst141

Samhouri, J. F., P. S. Levin, C. A. James, J. Kershner, and G. Williams. 2011. Using existing scientific capacity to set targets for ecosystem-based management: a Puget Sound case study. Marine Policy 35:508-518. https://doi.org/10.1016/j.marpol.2010.12.002

Shannon, L. J., M. Coll, A. Bundy, D. Gascuel, J. J. Heymans, K. Kleisner, C. P. Lynam, C. Piroddi, J. Tam, M. Travers-Trolet, and Y. Shin. 2014b. Trophic level-based indicators to track fishing impacts across marine ecosystems. Marine Ecology Progress Series 512:115-140. https://doi.org/10.3354/meps10821

Shannon, L. J., M. Coll, and S. Neira. 2009. Exploring the dynamics of ecological indicators using food web models fitted to time series of abundance and catch data. Ecological Indicators 9:1078-1095. https://doi.org/10.1016/j.ecolind.2008.12.007

Shannon, L., W. Osman, and A. Jarre. 2014a. Communicating changes in state of the southern Benguela ecosystem using trophic, model-derived indicators. Marine Ecology Progress Series 512:217-237. https://doi.org/10.3354/meps10879

Shin, Y.-J., A. Bundy, L. J. Shannon, J. L. Blanchard, R. Cheunpagdee, M. Coll, B. Knight, C. Lynam, G. Piet, A. J. Richardson, and the IndiSeas Working Group. 2012. Global in scope and regionally rich: an IndiSeas workshop helps shape the future of marine ecosystem indicators. Reviews in Fish Biology and Fisheries 22:835-845. https://doi.org/10.1007/s11160-012-9252$\underline{z}$ 
Shin, Y.-J., A. Bundy, L. J. Shannon, M. Simier, M. Coll, E. A. Fulton, J. S. Link, D. Jouffre, H. Ojaveer, S. Mackinson, J. J. Heymans, and T. Raid. 2010. Can simple be useful and reliable? Using ecological indicators to represent and compare the states of marine ecosystems. ICES Journal of Marine Science 67:717-731. https://doi.org/10.1093/icesjms/fsp287

Shin, Y.-J., and P. Cury. 2004. Using an individual-based model of fish assemblages to study the response of size spectra to changes in fishing. Canadian Journal of Fisheries and Aquatic Sciences 61:414-431. https://doi.org/10.1139/f03-154

Shin, Y.-J., J. E. Houle, E. Akoglu, J. L. Blanchard, A. Bundy, M. Coll, H. Demarcq, C. Fu, E. A. Fulton, J. J. Heymans, et al. 2018. The specificity of marine ecological indicators to fishing in the face of environmental change: a multi-model evaluation. Ecological Indicators 89:317-326. https://doi.org/10.1016/j. ecolind.2018.01.010

Shin, Y.-J., M.-J. Rochet, S. Jennings, J. G. Field, and H. Gislason. 2005. Using size-based indicators to evaluate the ecosystem effects of fishing. ICES Journal of Marine Science 62(3):384-396. https:// doi.org/10.1016/j.icesjms.2005.01.004

Shin, Y.-J., and L. J. Shannon. 2010. Using indicators for evaluating, comparing, and communicating the ecological status of exploited marine ecosystems. 1. The IndiSeas project. ICES Journal of Marine Science 67:686-691. https://doi.org/10.1093/ icesjms/fsp273

Smith, D. C., E. A. Fulton, P. Apfel, I. D. Cresswell, B. M. Gillanders, M. Haward, K. J. Sainsbury, A. D. M. Smith J. Vince, and T. M. Ward. 2017. Implementing marine ecosystem-based management: lessons from Australia. ICES Journal of Marine Science 74:1990-2003. https://doi.org/10.1093/icesjms/fsx113

Soma, K. 2003. How to involve stakeholders in fisheries management-a country case study in Trinidad and Tobago. Marine Policy 27:47-58. https://doi.org/10.1016/S0308-597X(02) $\underline{00050-7}$

Starfield, A., and N. Louw. 1986. Small expert systems: as perceived by a scientist with a computer rather than a computer scientist. South African Journal of Science 82:552-555.

Stelzenmüller, V., M. Coll, A. D. Mazaris, S. Giakoumi, S. Katsanevakis, M. E. Portman, R. Degen, P. Mackelworth, A. Gimpel, P. G. Albano, et al. 2018. A risk-based approach to cumulative effect assessments for marine management. Science of the Total Environment 612:1132-1140. https://doi.org/10.1016/j. scitotenv.2017.08.289

Stock, A., and F. Micheli. 2016. Effects of model assumptions and data quality on spatial cumulative human impact assessments. Global Ecology and Biogeography 25:1321-1332. https://doi.org/10.1111/geb.12493

Sutherland, W. J., L. Bellingan, J. R. Bellingham, J. J. Blackstock, R. M. Bloomfield, M. Bravo, V. M. Cadman, D. D. Cleevely, A. Clements, A. S. Cohen, et al. 2012. A collaboratively-derived science-policy research agenda. PLoS ONE 7:e31824. https://doi. org/10.1371/journal.pone.0031824

Tallis, H., P. S. Levin, M. Ruckelshaus, S. E. Lester, K. L. McLeod, D. L. Fluharty, and B. S. Halpern. 2010. The many faces of ecosystem-based management: making the process work today in real places. Marine Policy 34:340-348. https://doi.org/10.1016/j. marpol.2009.08.003

Tam, J. C., G. Fay, and J. S. Link. 2019. Better together: the uses of ecological and socio-economic indicators with end-to-end models in marine ecosystem based management. Frontiers in Marine Science 6:560. https://doi.org/10.3389/fmars.2019.00560

Tam, J. C., J. S. Link, S. I. Large, K. Andrews, K. D. Friedland, J. Gove, E. Hazen, K. Holsman, M. Karnauskas, J. F. Samhouri, et al. 2017. Comparing apples to oranges: common trends and thresholds in anthropogenic and environmental pressures across multiple marine ecosystems. Frontiers in Marine Science 4:282. https://doi.org/10.3389/fmars.2017.00282

Travers, M., Y.-J. Shin, S. Jennings, E. Machu, J. A. Huggett, J. G. Field, and P. M. Cury. 2009. Two-way coupling versus oneway forcing of plankton and fish models to predict ecosystem changes in the Benguela. Ecological Modelling 220:3089-3099. https://doi.org/10.1016/j.ecolmodel.2009.08.016

Travers-Trolet, M., Y.-J. Shin, L. J. Shannon, C. L. Moloney, and J. G. Field. 2014. Combined fishing and climate forcing in the southern Benguela upwelling ecosystem: an end-to-end modelling approach reveals dampened effects. PLoS ONE 9:e94286. https:// doi.org/10.1371/journal.pone.0094286

Turnhout, E., M. Hisschemöller, and H. Eijsackers. 2007. Ecological indicators: between the two fires of science and policy. Ecological Indicators 7:215-228. https://doi.org/10.1016/j. ecolind.2005.12.003

Walters, C., D. Pauly, V. Christensen, and J. F. Kitchell. 2000. Representing density dependent consequences of life history strategies in aquatic ecosystems: EcoSim II. Ecosystems 3:70-83. https://doi.org/10.1007/s100210000011

Walther, G. R., E. Post, P. Convey, A. Menzel, C. Parmesan, T. J. C. Beebee, J.-M. Fromentin, O. Hoegh-Gulderberg, and F. Bairlein. 2002. Ecological response to recent climate change. Nature 416:389-395. https://doi.org/10.1038/416389a

Yang, W., T. Dietz, D. B. Kramer, Z. Ouyang, and J. Liu. 2015. An integrated approach to understanding the linkages between ecosystem services and human well-being. Ecosystem Health and Sustainability 1:1-12. https://doi.org/10.1890/ehs15-0001.1

Zeileis, A., F. Leisch, K. Hornik, and C. Kleiber. 2002. strucchange: An R package for testing for structural change in linear regression models. Journal of Statistical Software 7(2)1-38. https://doi.org/10.18637/jss.v007.i02 


\section{Appendix 1}

\section{Example of Application of Framework in the Southern Benguela Ecosystem}

While full applications of the discussed framework to the Southern Benguela, South Catalan Sea and North Sea have been previously described (see Loclkerbie et al. Lockerbie et al., 2017a; Lockerbie et al., 2016; Lockerbie et al., 2017b, respectively), an example of its application is given here.

A suite of eleven IndiSeas indicators, including six ecological indicators (mean fish length, mean lifespan, survey biomass, proportion of predators and trophic levels of both modelled and surveyed communities) and five fishing pressure indicators (inverse fishing pressure, landings, marine trophic index, trophic level of landings and the intrinsic vulnerability index), were utilised across all ecosystems. In the case of the Southern Benguela an additional four environmental indicators were selected which were considered to represent the most important environmental drivers in the ecosystem; sea surface temperature, chlorophyll concentration, upwelling and the position of the South Atlantic high pressure system.

Trends in all indicators were determined using linear regressions (time series plots can be seen in Figure A1), and each indicator received a score based on the significance and directions of detected trends; highly significant positive trend $=1$, ecologically significant positive trend $=$ 2 , no significant trend $=3$, ecologically significant negative trend $=4$ and highly significant negative trend $=5$. A score adjustment system was developed (Figure 2), following detailed sensitivity analysis (see Lockerbie et a., 2016), to modify scores to account for the impacts of both fishing pressure and environmental variability on ecological indicators. Fishing pressure indicators were combined, as described above, into an indicator of overall fishing pressure, and it is this indicator that was utilised to determine whether ecological indicator trends resulted from the observed trend in fishing pressure. Score adjustment was based on both the direction of the trend in fishing pressure, and to what extent fishing pressure could explain the observed trend in an ecological indicator. Following this initial score adjustment, it was necessary to determine whether the trends in environmental indicators would have influenced the observed ecological indicator trends. At this stage, due to the complex nature of ecosystems, it is not possible to determine whether the identified environmental change would be positive or negative for the ecosystem, as various species will respond differently. Therefore, this adjustment involved dividing the indicator score depending on the extent to which environmental variability was thought to have impacted the ecological indicators, acting to lessen the impacts of fishing on the indicator in question and signifying that fishing pressure was not the sole cause of the observed ecological indicator trend. Finally, scores were adjusted to account the possible redundancy of correlated indicators by applying different weightings to correlated and non-correlated indicators. This weighting acted to reduce the contribution of 
correlated indicators to the overall ecosystem score. It was necessary for this final adjustment to be ecosystem specific, as different indicators were correlated in different ecosystems.

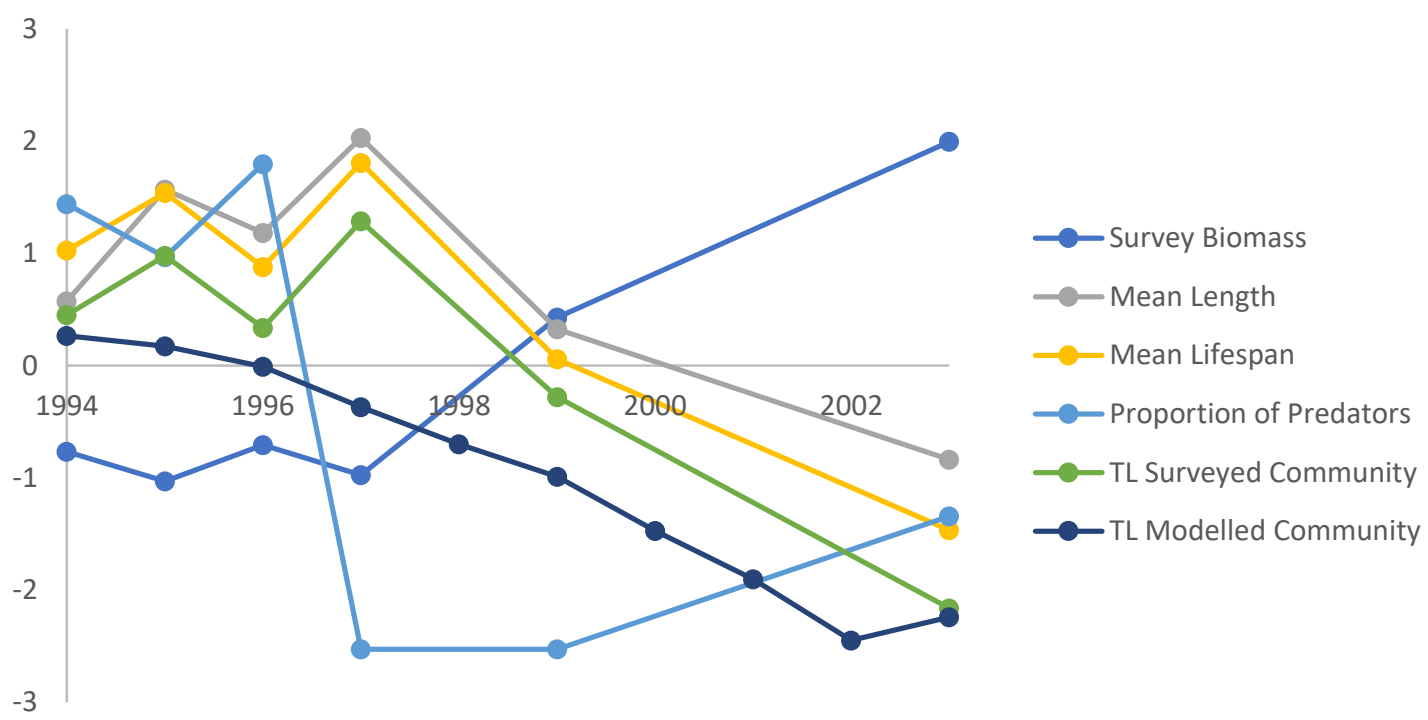

Figure A1: Time series plot of indicators values for Period 2 (1994-2003)

This process was applied to each of the three periods in turn, classifying the state of the ecosystem in each. Table A1 shows summarised results from the assessment of Period 2 (1994-2003) in the Southern Benguela. When applying the score adjustment to the framework it is necessary to provide details to ensure the correct interpretation of indicator trends. While IndiSeas indicators have been formulated so that a decreasing trend is considered to represent a negative change within an ecosystem, other factors may come into play. Therefore, at this stage the considerable importance of including expert knowledge was highlighted, with regional experts ensuring accurate understanding of ecological changes represented by the indicator trends. For example, in Period 2, when there was a decrease in fishing pressure, the negative scores observed in numerous indicators were unexpected (see Table A1). However, through use of expert knowledge alongside information gained from literature, it was possible to relate the highly significant negative trends observed in mean lifespan, proportion of predators and the trophic levels of both the modelled and surveyed communities to a short-lived but significant increase in small pelagic fish in the early 2000s (Roy et al., 2001). This increase in small pelagic species was significant enough to alter indicators trends over the entire period, with negative trends not representing a negative influence of fishing pressure on the ecosystem. 
Table A1: Summary of outputs of decision tree framework for Period 2 (1994-2003) in the Southern Benguela. Scores are sequentially adjusted to account for the influences of fishing pressure and environmental variability. A weighted mean is used to account for potential redundancies and calculate a final score, classifying the ecosystem. See footnotes for details on how the observed fishing pressure and environmental indicator trends impact each indicator (Adjusted from Lockerbie et al. 2016).

\begin{tabular}{|c|c|c|c|c|c|}
\hline & \multicolumn{5}{|c|}{ Period 2 (1994-2003) } \\
\hline Indicator & $\begin{array}{l}\text { Original } \\
\text { Score }\end{array}$ & $\begin{array}{l}\text { Trends in } \\
\text { fishing } \\
\text { pressure \& did } \\
\text { fishing } \\
\text { pressure cause } \\
\text { this trend? }\end{array}$ & New Score & $\begin{array}{l}\text { Did the } \\
\text { environment } \\
\text { influence this } \\
\text { trend? }\end{array}$ & Final Score \\
\hline Mean Length & 3 & $\begin{array}{l}\text { Decreasing } \\
\text { - Partiallyi }\end{array}$ & 2.25 & $Y_{e s}^{v}$ & 1.5 \\
\hline Mean Lifespan & 5 & $\begin{array}{l}\text { Decreasing } \\
-\mathrm{No}^{\mathrm{ii}}\end{array}$ & 5 & $Y_{e s}^{v}$ & 3.33 \\
\hline Biomass & 1 & $\begin{array}{l}\text { Decreasing } \\
- \text { Yes }^{\mathrm{iii}}\end{array}$ & 0.5 & $Y^{\mathrm{vi}} \mathrm{s}^{\mathrm{i}}$ & 0.33 \\
\hline $\begin{array}{l}\text { Proportion of } \\
\text { Predators }\end{array}$ & 5 & $\begin{array}{l}\text { Decreasing } \\
\text { - No }\end{array}$ & 5 & Partiallyvii & 4 \\
\hline $\begin{array}{l}\text { Trophic Level of } \\
\text { Surveyed Community }\end{array}$ & 5 & $\begin{array}{l}\text { Decreasing } \\
\text { - No }\end{array}$ & 5 & Yes $^{\text {viii }}$ & 3.33 \\
\hline $\begin{array}{l}\text { Trophic Level of } \\
\text { Modelled Community }\end{array}$ & 5 & $\begin{array}{l}\text { Decreasing } \\
-\mathrm{No}^{\mathrm{iv}}\end{array}$ & 5 & Yes $^{\text {viii }}$ & 3.33 \\
\hline Mean Score & 4 & & & & 2.64 \\
\hline Weighted Mean & & & & Ecosystem score: & 2.56 \\
\hline
\end{tabular}

${ }^{\mathrm{i}}$ Overall fishing pressure decreased, therefore increased mean fish length may be expected due to decreased pressure on the ecosystem. Lack of change in mean fish length likely resulted from increases in small pelagic fish during this period while predators have not yet started to recover (Roy et al., 2001).

ii Overall fishing pressure decreases, therefore a significant decrease in mean lifespan would not be expected due to decreased pressure at all trophic levels. The highly significant decrease observed here is likely a result of an increase in small pelagic fish that was observed during this period (Roy et al., 2001).

iii Overall fishing pressure decreased; therefore, increased biomass within the ecosystem would be expected because of reduced mortality.

iv Overall fishing pressure decreased, therefore decreased proportion of predators and trophic level of both the surveyed and modelled communities would not be expected. May be have resulted from the unusual and short-lived increase in small pelagics (Roy et al., 2001) while predatory fish populations had not yet shown a recovery.

${ }^{v}$ Observed offshore movement of the South Atlantic High Pressure System along with variability in upwelling (both increases and decreases are observed at different locations). This would influence nutrients and primary production as well as dispersal and recruitment impacting all levels of the ecosystem. This, along with variability in upwelling (see Lockerbie et al. [1] - Table 3) may have influenced mean length and lifespan of fish as certain environmental conditions favoured certain species. A shift towards conditions which favoured small pelagic species, and their subsequent increase in abundance, could explain the decrease in mean lifespan (Connolly et al., 2001; Gaylord and Gaines, 2000; Rochet and Trenkel, 2003).

${ }^{v i}$ Observed offshore movement of the South Atlantic High Pressure System along with variability in upwelling (both increases and decreases are observed at different locations). This would influence will influence primary productivity, 
Cole, J., and J. McGlade. 1998. Clupeoid population variability, the environment and satellite imagery in coastal upwelling systems. Reviews in Fish Biology and Fisheries 8: 445-471.

Connolly, S. R., B. A. Menge, and J. Roughgarden. 2001. A latitudinal gradient in recruitment of intertidal invertebrates in the Northwest Pacific Ocean. Ecology 82: 1799-1813.

Gaylord, B., and S. D. Gaines. 2000. Temperature or transport? Range limits in marine species mediated solely by flow. The American Naturalist 155: 769-789.

Lockerbie, E., M. Coll, L. J. Shannon, and A. Jarre. 2017a. The Use of Indicators for Decision Support in Northwestern Mediterranean Sea Fisheries. Journal of Marine Systems 174: 64-77. Lockerbie, E., L. Shannon, and A. Jarre. 2016. The use of ecological, fishing and environmental indicators in support of decision making in southern Benguela fisheries. Ecological Indicators 69: 473-487.

Lockerbie, E. M., C. P. Lynam, L. Shannon, and A. Jarre. 2017b. Applying a decision tree framework in support of an ecosystem approach to fisheries: IndiSeas indicators in the North Sea. ICES Journal of Marine Science 75: 1009-1020.

Rochet, M.-J., and V. M. Trenkel. 2003. Which community indicators can measure the impact of fishing? A review and proposals. Canadian Journal of Fisheries and Aquatic Sciences 60: 86-99. Roy, C., S. J. Weeks, M. Rouault, C. S. Nelson, R. G. Barlow, and C. D. van Der Lingen. 2001. Extreme oceanographic events recorded in the Southern Benguela during the 1999-2000 summer season. South African Journal of Marine Science 97: 465-471. 